\title{
Musculoskeletal Risks: RULA Bibliometric Review
}

\author{
Marta Gómez-Galán ${ }^{1}$, Ángel-Jesús Callejón-Ferre ${ }^{1,2, * ®}$, José Pérez-Alonso ${ }^{1}($, \\ Manuel Díaz-Pérez ${ }^{1}$ (D) and Jesús-Antonio Carrillo-Castrillo ${ }^{3}$ (D) \\ 1 Department of Engineering, University of Almería, Research Center CIMEDES (CeiA3), 04120 Almería, \\ Spain; mgg492@ual.es (M.G.-G.); jpalonso@ual.es (J.P.-A.); madiaz@ual.es (M.D.-P.) \\ 2 Laboratory-Observatory Andalusian Working Conditions in the Agricultural Sector (LASA), 41092 Seville, \\ Spain \\ 3 School of Industrial Engineering, University of Seville, 41092 Seville, Spain; jcarrillo3@us.es \\ * Correspondence: acallejo@ual.es; Tel.: +34-950-214-236; Fax: +34-950-015-491
}

Received: 30 May 2020; Accepted: 15 June 2020; Published: 17 June 2020

\begin{abstract}
The objective of this study was to reveal RULA method applications in terms of the knowledge, country, year and journal categories. The search was performed using the "Web of Science Core Collection". The period from 1993 to April 2019 was selected. Eight hundred nine results were obtained, of which 226 were used. The largest number of publications was determined to be in the fields of industry and health and social assistance, which coincides with the OWAS and Standardized Nordic Questionnaire methods. By country, the USA stands out for its greater number of research studies and categories that are encompassed. By date, 2016 was the year when more studies were carried out, again coinciding with the Standardized Nordic Questionnaire. By journal, "Work-A Journal of Prevention Assessment and Rehabilitation" is highlighted, as it is for the REBA method as well. It was concluded that RULA can be applied to workers in different fields, usually in combination with other methods, while technological advancement provides benefits for its application.
\end{abstract}

Keywords: biomechanics; musculoskeletal disorders; RULA; ergonomics; applications

\section{Introduction}

\subsection{Musculoskeletal Disorders (MSD)}

One of the most common work diseases in Europe are musculoskeletal disorders. These appear in various areas of the body, the most common developing in the back and upper extremities [1].

Among the causes that stand out for their appearance are the physical (manual, forced or frequently repeated movements, harmful postures and vibrations, etc.) and those relating to work organisation (high work rate, schedule, routine work, etc.) [2].

This type of disorder has numerous consequences for the affected worker, but also for businesses and countries (at the economic level) [3].

To prevent this occupational disease, it is necessary to identify all the risk factors that occur during work. Once determined, preventive measures should be taken to avert them, or actions taken to reduce them [2]. Some authors propose measures such as rotating workers between different jobs [4], providing ergonomic training to workers [5], designing ergonomic tools for MSD analysis in the workplace [6], redesigning work equipment from the ergonomic perspective [7], etc.

\subsection{Assessment Methods}

There are numerous methods for assessing musculoskeletal disorders. These can be classified into three main groups: direct, semi-direct and indirect (Table 1 [8]). 
Table 1. Types of MSD assessment methods [8].

\begin{tabular}{ccc}
\hline Direct & Semi-Direct & Indirect \\
\hline $\begin{array}{c}\text { Placing sensors on workers' } \\
\text { bodies as they perform tasks. }\end{array}$ & $\begin{array}{c}\text { Observing the task being carried out } \\
\text { and using software to analyse it. }\end{array}$ & Employing questionnaires. \\
\hline
\end{tabular}

Of the three groups above, the most economical methods are the indirect ones since they are based solely on completing questionnaires. The opposite is true in the other two cases as software licenses are required and sensors have to be purchased. Direct methods are the most accurate because they provide virtually automatic information. In terms of complexity, direct and indirect methods stand out-in the former because the use of sensors can be a nuisance for the worker and, in the latter, because of the subsequent statistical analysis [8].

When selecting a method for a particular study, it is advisable to consider several criteria (cost, accuracy, complexity, application time, etc.) and to analyse the advantages and disadvantages of each.

\subsection{Examples of Direct, Semi-Direct and Indirect Methods}

The following are some examples of direct, semi-direct, and indirect assessment methods (Figure 1; Figure 2; [9-13]; [14-30]).

\section{DIRECT METHODS}

HADA Move-Human

Sensors System

\section{INDIRECT METHODS}

Standardised Nordic Questionnaire

Quick Exposure Check Questionnaire

Michigan Questionnaire

Figure 1. Examples of direct and indirect methods.

\section{SEMIDIRECT METHODS}

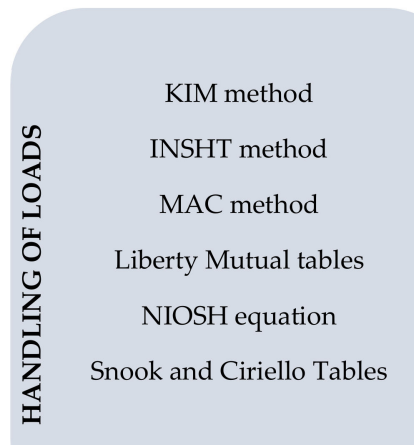

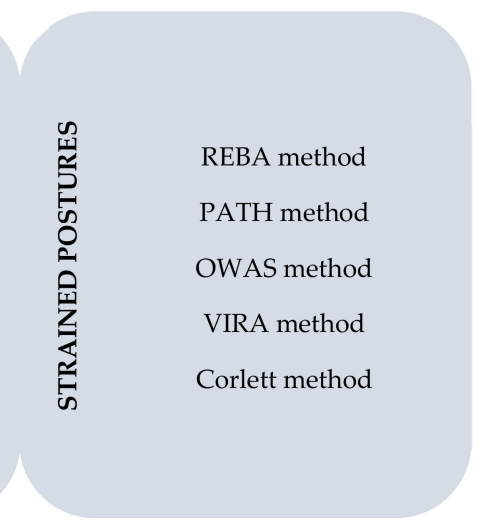

Figure 2. Examples of semi-direct methods (see Appendix A).

\subsection{Rapid Upper Limb Assessment (RULA) Method}

The RULA method was designed in 1993 by McAtamney and Corlett. Its objective is to know if workers are exposed to MSD risk factors in the upper extremities during the performance of their work [20].

The method assesses three factors: the posture of the different areas of the body, the load or force exerted and the muscle activity (static posture or repetitive movements). The body regions which RULA focuses on are divided into two groups [31]:

- Group A: arm, forearm, wrist and wrist turn.

- Group B: neck, torso and legs. 
- Three main stages [20,31] are performed to carry out the assessment using this method:

- Observation of postures. This is done while the worker performs the task and can be realised in three ways: direct observation or by taking images or videos. The postures to be assessed (those most repeated, those performed for more than $10 \%$ or $15 \%$ of the task and those that are most harmful) are selected. Only one side of the body is analysed, namely the one which suffers most harm; however, if they are very different, then both sides are assessed.

- Scores. For the postures to be assessed, the angle must be measured between each of the body areas and the vertical. The lower extremities are not measured, although it is taken into account whether the posture is balanced and supported. Using these data, which are modified by different criteria and considering the load factors and muscle activity, the RULA scores are calculated (Figure 3).

- Action levels. From the final scores, one obtains the action level. RULA differentiates four levels:

$>\quad$ Level 1 (Score: $1-2)$. No action is needed.

$>\quad$ Level 2 (Score: 3-4). Measures should be taken, but not in the short term.

$>\quad$ Level 3 (Score 5-6). Measures should be taken in the short term.

$>\quad$ Level 4 (Score 7). Urgent action must be taken.

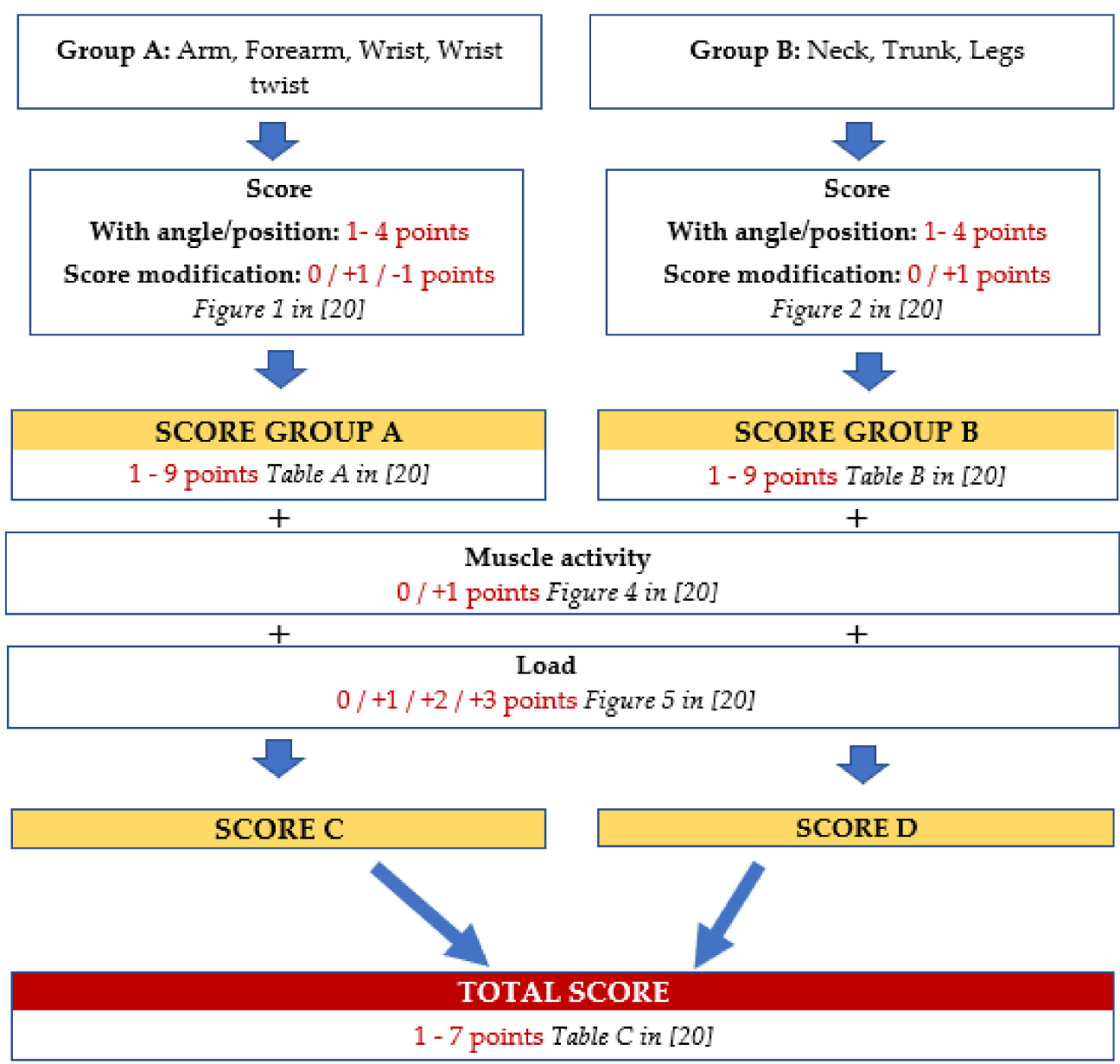

Figure 3. RULA Scores [20,31].

\subsubsection{Advantages}

Some advantages of the RULA method include: 
- It is a reliable method to use for repetitive tasks, mainly in the upper limbs [31].

- It has been applied to workers across very different areas [31].

- The assessor needs no experience in order to apply it during the observation phase [20].

- It is not very complex to apply. The method is simple to use [32].

- It can be applied with the help of software [31,32].

\subsubsection{Limitations}

Among the disadvantages of the RULA method are the following:

- It results in a high-level risk for non-permanent jobs [31].

- The left and right side of the body are assessed independently [32].

- It does not take into account the time the worker takes to carry out the task [32].

\subsection{Objective}

The aim of this work is to review all the studies in which the RULA method has been applied from 1993 to April 2019 and to analyse them according to the following categories: knowledge, country, year and journal.

\section{Materials and Methods}

To search for information about the different RULA method applications, the University of Almería's library website was accessed. There, we used the "Web of Science" (WoS) database, the license of which is managed by the Spanish Foundation for Science and Technology (FECYT).

The search was done by selecting the "Web of Science Core Collection" and the advanced search option, in which "so = Applied Ergonomics" was introduced. The "Create Citation Reports" option was selected. In this way, the total number of available citations was consulted for the original article proposing the RULA method by McAtamney and Corlett [20].

The number of studies obtained was 809, in the period from 1993 to 29 April 2019. Of these, using the title and abstract of each study, we finally selected a total of 226 results, discarding those that did not include the method's application. The final studies were from 1998 to 2019.

It should be noted that the main limitation of the information search is that we only used the Web of Science Core Collection; no other databases were accessed. Therefore, some studies may have been overlooked with the search method used.

\section{Results and Discussion}

The studies obtained from the search have been analysed and classified according to the categories of knowledge, location (countries), publication date (years) and journals.

\subsection{Classification by Knowledge Categories}

A particular classification [33] has been used to order the RULA studies according to the knowledge categories. Table 2 shows the different areas presented, the designated nomenclature and the number of published studies. 
Table 2. Knowledge categories [33].

\begin{tabular}{cc}
\hline Knowledge Category & Number of Studies \\
\hline Agriculture, forestry and fishing & 18 \\
Mining and quarrying & 2 \\
Manufacturing & 74 \\
Construction & 1 \\
Water supply; sewerage, waste management and remediation activities & 4 \\
Wholesale and retail trade; repair of motor vehicles and motorcycles & 3 \\
Transportation and storage & 12 \\
Accommodation and food service activities & 3 \\
Information and communication & 9 \\
Financial and insurance activities & 1 \\
Professional, scientific and technical activities & 2 \\
Administrative and support service activities & 12 \\
Public administration and defence; compulsory social security & 2 \\
Education & 12 \\
Human health and social work activities & 38 \\
Arts, entertainment and recreation & 3 \\
Other service activities & 3 \\
Activities of households as employers; undifferentiated goods and & 2 \\
services producing activities of households for own use & 25 \\
Other scopes not previously included * & 2 \\
\hline
\end{tabular}

* The category "Other areas not previously included" is not part of the classification used; it is a section that encompasses studies that have not been considered in the other fields.

In total, 19 categories are differentiated. One can observe that "Manufacturing" stands out as having more studies than the rest, a total of 74 . This is followed by 38 and 25 publications corresponding to "Human health and social work activities" and "Other areas not previously included ", respectively (Table 2).

In contrast, two fields are differentiated in which only one research study is recorded-“Water supply, sewerage, waste management and remediation activities" and "Financial and insurance activities" (Table 2).

Figure 4 shows the different areas of knowledge based on the frequency of the published studies.

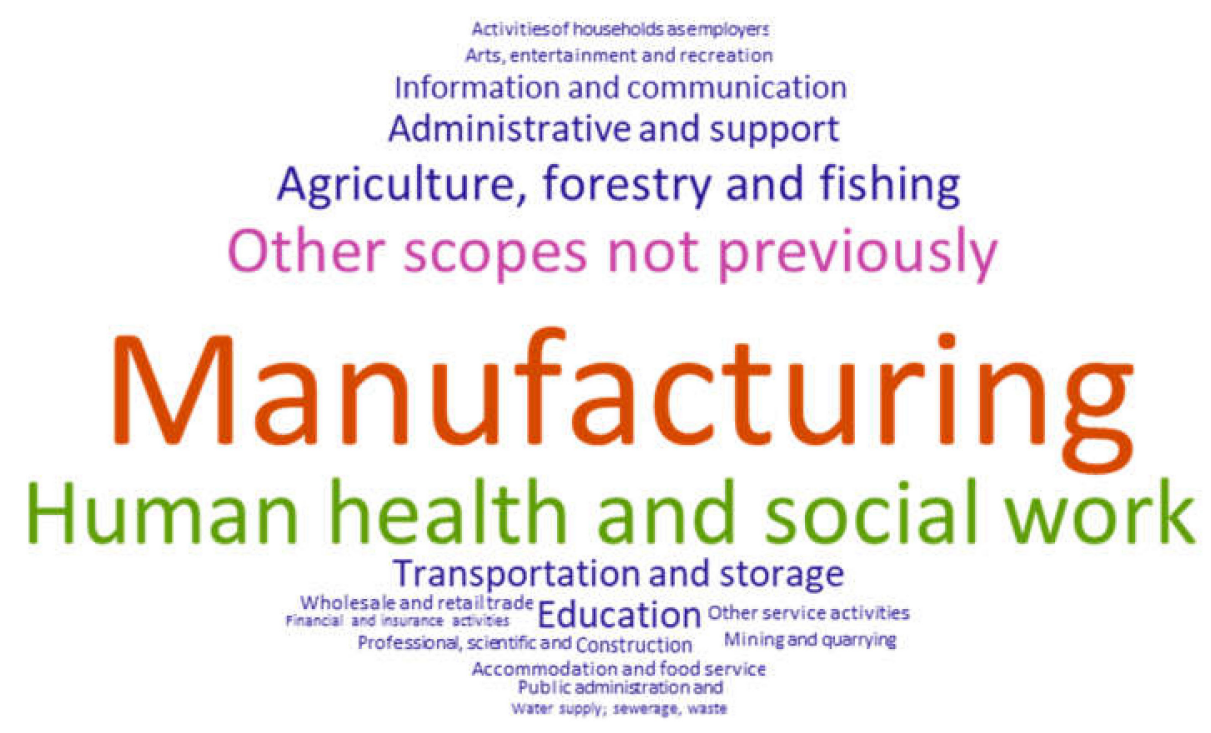

Figure 4. Knowledge categories and frequency.

Below is a description of each of these categories [33]. 


\subsubsection{Agriculture, Forestry and Fishing}

Table 3 summarises the studies related to this category.

Table 3. Agriculture, forestry and fishing.

\begin{tabular}{|c|c|c|c|}
\hline Reference & Year & Country & Study Objective \\
\hline [34] & 2019 & Italy & RULA and REBA assessment of a forestry worker using a wood-chipper machine. \\
\hline [35] & 2018 & Thailand & $\begin{array}{c}\text { Design of a knife to improve the ergonomics for workers who collect rubber. BCTQ and RULA were used for } \\
\text { the assessment. }\end{array}$ \\
\hline [36] & 2018 & USA & Use of RULA and other ergonomic tools on blueberry harvesters. \\
\hline [37] & 2018 & India & Application of OWAS, RULA, REBA, QEC and others on rice growing workers. \\
\hline [38] & 2018 & Thailand & Use of the Musculoskeletal Nordic Questionnaire, RULA and a tasks checklist in hazardous places for fruit farmers. \\
\hline [39] & 2018 & India & $\begin{array}{c}\text { Implementation of the modified Standardized Nordic Questionnaire and the RULA method on farm workers } \\
\text { performing manual tasks. }\end{array}$ \\
\hline [40] & 2018 & Spain & Use of RULA, REBA and OWAS on olive farm workers during the task of pruning with a chainsaw. \\
\hline [41] & 2018 & India & $\begin{array}{c}\text { Use of the Musculoskeletal Nordic Questionnaire and the RULA method on farm workers engaged in } \\
\text { manual harvesting. }\end{array}$ \\
\hline [42] & 2018 & $\begin{array}{l}\text { South } \\
\text { Korea }\end{array}$ & $\begin{array}{l}\text { Comparison of the ALLA method with RULA, REBA and OWAS using the assessment of postures developed } \\
\text { in agriculture. }\end{array}$ \\
\hline [43] & 2017 & Turkey & Application of REBA, RULA, QEC and OWAS on nursery workers. \\
\hline [44] & 2016 & Indonesia & RULA assessment on workers who use threshing machines for rice cultivation. \\
\hline [45] & 2016 & Spain & Application of RULA on farm workers performing crop stringing \\
\hline [46] & 2016 & Malaysia & Assessment using RULA and other ergonomic tools on workers responsible for cutting oil palm. \\
\hline [47] & 2014 & Malaysia & Application of RULA on workers charged with oil palm collection. \\
\hline [48] & 2013 & Malaysia & Use of RULA on oil palm harvesters. \\
\hline [49] & 2013 & Thailand & $\begin{array}{l}\text { Use of the Industrial Ergonomics Screening Tool, based on HAL (Hand Activity Level) and RULA methods on } \\
\text { workers during rice cultivation ploughing with a cultivator. }\end{array}$ \\
\hline$[50]$ & 2012 & Italy & $\begin{array}{l}\text { Conducting a study with the aim of redesigning the space for the driver of an agricultural tractor. Catia V5 } \\
\text { software and other tools, including RULA, were used. }\end{array}$ \\
\hline [51] & 2012 & Thailand & Use of a survey, a form and RULA on rubber harvesters. \\
\hline
\end{tabular}

Crop and Animal Production, Hunting and Related Service Activities

The RULA method has been used for the ergonomic assessment of farm workers working on various crops or specific tasks.

In fruit crops, Thetkathuek et al. [38] applied it together with the Nordic Musculoskeletal Questionnaire and a tasks checklist. In total, 861 farm workers took part in Thailand. They showed that men with more than 10 years of experience had their necks most affected and women their lower backs. In blueberry harvesting, Kim et al. [36] used it in conjunction with the Borg CR10 scale, electromyography, the Cumulative Trauma Disorders (CTD) index and NIOSH (National Occupational Institute for Safety and Health). They concluded that the risk was reduced by carrying out the work with the help of machinery.

Three studies were carried out on oil palm harvesting. In two of them, other ergonomic tools were also used. In the first study, 109 workers were assessed, while three and seven were assessed in the other two. The results for all three showed that most workers were exposed to a very high level of risk when carrying out the tasks. Changes were required as a matter of urgency [46-48].

Three other studies were conducted into rice cultivation. Pal and Dhara [37] studied 166 workers in India. They also used other methods such as REBA (The Rapid Entire Body Assessment), OWAS (The Ovako Working Analysis System), etc. The results showed the frequent appearance of MSD, with the most affected areas being the lumbar, hip, wrist, shoulder and knee regions. In the other two studies, farm workers were assessed when using machinery during the tasks: in one case using threshing machines and in the other using a cultivator. For both, it was concluded that there was a high risk of MSD [44,49].

In olive cultivation, Pardo-Ferreira et al. [40] assessed farm workers performing pruning with a chainsaw. Other methods were also used, in particular REBA and OWAS. They determined that change was needed, as workers were exposed to ergonomic risks. 
Another series of studies was conducted using the RULA method to assess different tasks. Jain et al. [39,41] carried out two studies focusing on manual tasks, also using a questionnaire. The first concluded the frequent development of musculoskeletal disorders in workers; this coincided with the second, which indicated a score (RULA) of 5 or above for $92 \%$ of the workers.

Vazquez-Cabrera [45] investigated farm workers during crop stringing. They simulated different ways to do it in a laboratory according to the height, crop weight and guides used. Among other findings, heights of $1.4 \mathrm{~m}$ were shown to be acceptable, with 1.2 and $1.6 \mathrm{~m}$ heights also being possible. Weights over $2 \mathrm{~kg}$ were found not to be suitable.

Finally, some authors set out specific objectives. Kong et al. [42] used RULA to assess Korean farm workers as they adopted 96 postures. The aim was to apply RULA along with the REBA, OWAS and ALLA (Agricultural Lower Limb Assessment) methods in order to compare the last one with the previous three, proving it to be the most correct. Di Gironimo et al. [50] set out to redesign and improve the ergonomics of an agricultural tractor's driver space. In addition to RULA, this was done using Catia V5 software (as well as other ergonomic tools) to design a 3D model. Some devices in the cab needed to be corrected to provide better ergonomics.

Forestry and Logging

Studies in this category using the RULA method have only been carried out in forestry.

Several authors focused on rubber harvesting workers (tappers). Meksawi et al. [51] also used a survey and a form. According to the RULA results, an action Level 3 was obtained, so changes needed to be made to the work. Pramchoo et al. [35] assessed the ergonomics of a new knife designed for tapping. Two groups participated, one of them using the new knife. In each group, half of the workers suffered discomfort related to the carpal tunnel syndrome. The Boston Carpal Tunnel Syndrome Questionnaire (BCTQ) was also applied. The new knife, among other advantages, reduced the discomfort from carpal tunnel syndrome in sufferers and improved the wrist posture.

Regarding forestry activity, two studies were performed to assess workers. Cremasco et al. [34] focused on tasks performed with a wood-chipper; they also used REBA in their assessment. Unver-Okan et al. [43] focused on forestry nurseries; they also employed REBA, OWAS and QEC (Quick Exposure Check). In both cases, it was determined that the RULA method was the most suitable for such assessments.

\subsubsection{Mining and Quarrying}

Table 4 presents the only two studies related to this category.

Table 4. Mining and quarrying.

\begin{tabular}{cccc}
\hline Reference & Year & Country & Study Objective \\
\hline$[52]$ & 2010 & India & $\begin{array}{c}\text { Use of REBA, RULA, OCRA and other } \\
\text { ergonomic tools on stone carving workers. } \\
\text { Application of RULA on mine workers. }\end{array}$ \\
\hline 53$]$ & 2016 & Malaysia & Aplon
\end{tabular}

In this field of knowledge, there are only two studies available in which the RULA method was applied—one for the ergonomic assessment of mine workers and the other, together with the REBA and OCRA (Occupational Repetitive Action) methods, in stone-carving workers. Both studies concluded that very high risks existed that required immediate changes [52,53].

\subsubsection{Manufacturing}

Table 5 sets out the different publications available in the field of manufacturing. 
Table 5. Manufacturing.

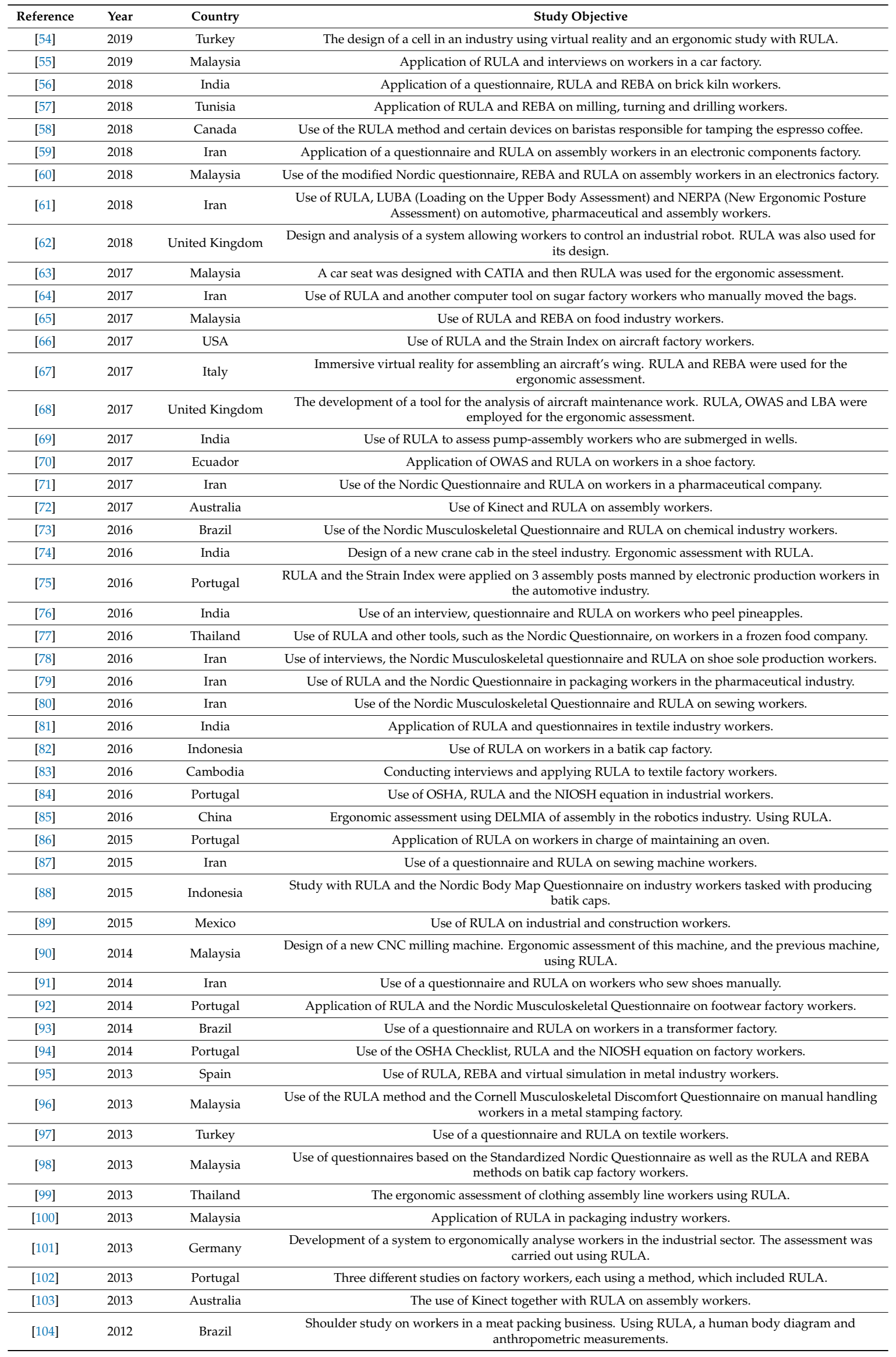


Table 5. Cont.

\begin{tabular}{|c|c|c|c|}
\hline Reference & Year & Country & Study Objective \\
\hline [105] & 2012 & Taiwan & $\begin{array}{l}\text { Study using 3D simulation to introduce humans into a robot workplace, working with fruits and vegetables. } \\
\text { Ergonomic analysis using LBA and RULA. }\end{array}$ \\
\hline [106] & 2012 & USA & Application of the RULA method and two other tools on mobile phone assembly workers. \\
\hline [107] & 2012 & Netherlands & Ergonomic assessment with RULA on laptop manufacturing workers. \\
\hline [108] & 2012 & Iran & Use of RULA and the Nordic Musculoskeletal Questionnaire on textile workers. \\
\hline [109] & 2012 & Thailand & Application of REBA, RULA and OWAS on rubber sheet manufacturing workers. \\
\hline [111] & 2012 & Canada & Use of 8 methods, including RULA, on industrial workers. \\
\hline [112] & 2012 & Germany & Use of RULA to assess a humanoid robot arm with human-like postures. \\
\hline [113] & 2011 & Turkey & Use of the adapted Nordic Musculoskeletal Questionnaire and RULA on textile workers. \\
\hline [114] & 2011 & Indonesia & $\begin{array}{l}\text { Use of a virtual space with a human model to ergonomically assess workers in a textile business. One of the } \\
\text { methods used was RULA. }\end{array}$ \\
\hline [119] & 2010 & India & Ergonomic assessment with RULA of assembly line workers. \\
\hline [120] & 2008 & Canada & Use of various methods, including RULA, on sawmill workers. \\
\hline [121] & 2007 & Canada & Use of 5 assessment methods, including RULA, on sawmill workers. \\
\hline [122] & 2007 & South Korea & $\begin{array}{c}\text { Use of REBA, RULA and OWAS on workers from various industries such as the electronics, steel, chemical } \\
\text { and automotive industries. }\end{array}$ \\
\hline [123] & 2006 & Portugal & $\begin{array}{l}\text { Using RULA, Surface EMG, a questionnaire, and a clinical examination on paint workers in the automotive } \\
\text { industry. }\end{array}$ \\
\hline [124] & 2004 & Germany & $\begin{array}{l}\text { Study of the benefits of employing a human digital model in the automotive industry and ergonomic } \\
\text { assessment with RULA. }\end{array}$ \\
\hline [125] & 2004 & Iran & Ergonomic analysis with RULA of workers in rug-fixing workshops. \\
\hline
\end{tabular}

Manufacture of Motor Vehicles, Trailers and Semi-Trailers

The RULA method was used in four research studies to ergonomically assess automotive workers. Each focused on various tasks such as painting, assembly and others. One of the studies used a human digital model, obtaining some benefits from its use [124]. In the others, in addition to the RULA method, other assessment tools were applied. It was concluded that the risk of musculoskeletal disorders existed. Two of them yielded high-level risks [55,75,123]. On the other hand, Mat et al. [63] used RULA to ergonomically assess a car seat. The seat was analysed after being designed with CATIA software and optimisation was performed. This showed a decrease in the level of risk.

Manufacture of Other Non-Metallic Mineral Products

Sain and Meena [56] used RULA, REBA and a questionnaire to perform an ergonomic analysis on brick furnace personnel. They concluded that some tasks needed to be modified as there was a risk of musculoskeletal disorders. Coinciding with this need to take action, Monteil et al. [115] employed RULA via a digital human model on roof slate manufacturing workers.

\section{Manufacture of Fabricated Metal Products, Except Machinery and Equipment}

The RULA method was used by Boulila et al. [57] along with REBA and a survey on milling, turning and drilling workers. Twelve postures were determined to negatively influence job performance. In relation to this, other authors redesigned a CNC milling machine to take worker ergonomics into account. They used RULA to analyse the postures assumed in the initial machine and those in the new design, with the latter being less harmful [90].

In addition, two studies found high risk levels according to the RULA method. The first was carried out on workers performing manual handling work in a metal stamping business. The Cornell 
Musculoskeletal Discomfort Questionnaire (CMDQ) [96] was also used. The second study focused on cutlery polishing workers [116].

Finally, some authors [126] studied the relationship between ergonomics at work and product quality in the metallurgical industry. RULA was used and, as a result, the work carried out was modified. Quality improvements were identified in the newly-produced products.

\section{Food Product Manufacture}

The RULA method was used in conjunction with REBA in the food industry. It was concluded that workers adopted postures that could lead to musculoskeletal disorders [65]. Similar results were obtained by applying RULA together with other assessment tools on pineapple peeling workers, obtaining a risk Level 3 assessment [76]. It was also applied in a sugar factory assessing the bag movement task. A high-risk level was determined [64].

In two other cases, negative results were shown for certain body regions. One of them applied the method to a frozen food business, along with other tools such as the Nordic Questionnaire. This was applied to both production and office workers. The greatest discomfort appeared at the elbow [77]. The other focused on workers in a meat packing factory. RULA, a human body diagram and anthropometric measurements were used. The shoulder was shown to be at risk. It was concluded that corrective measures were required [104].

Other authors used 3D simulation and the I-DEAS programme to replace the work of a robot (used for processing fruits and vegetables) with a worker. RULA and LBA (Lower Back Analysis) were employed for the ergonomic analysis. The results found a particular posture that the seated worker could adopt to avoid a high risk to the lower back and upper limbs [105].

Finally, a study was carried out on baristas tasked with tamping espresso coffee. RULA was used in conjunction with sensors placed on the column and a force plate. Lower scores were shown when using a flat tamper rather than a traditional one [58].

Manufacture of Computer, Electronic and Optical Products

According to RULA, assembly tasks in the electronics industry indicate high levels of risk for the workers who perform them. Two studies demonstrated this, the first applied the RULA method along with a questionnaire while carrying out an intervention to achieve more comfortable postures. The other supplemented it with REBA and the modified Nordic Questionnaire. Both agreed that the body areas most affected by MSD were the lumbar region and the wrists. However, one of them also included the hands and neck while the other included the shoulders [59,60].

Other authors set out to reduce neck discomfort in mobile phone assembly workers. To do this, they performed an ergonomic intervention. An assessment, using the RULA method and other tools, was carried out before and after the intervention. Improved worker ergonomics were achieved following the intervention [106,117].

Something similar was done during the manufacture of laptops. Materials were reused and two carts were created, one for refuse collection and the other for sorting and distributing labels. An assessment was carried out with RULA before and after using the new carts. Better ergonomic and work results were obtained [107].

\section{Manufacture of Other Transport Equipment}

The RULA method was used in three studies developed in the same year which looked into aircraft manufacturing. The purpose was to assess worker ergonomics. One of the studies also used the Strain Index demonstrating a relationship among work design, performance and ergonomics [66]. In another, RULA was used in conjunction with REBA to assess aircraft wing component assembly using immersive virtual reality to perform the task [67]. Finally, a maintenance work analysis tool was developed using CATIA software. RULA, OWAS and LBA [68] were employed together. 
Manufacture of Machinery and Equipment N.E.C.

In this area, the RULA method was used in a single study. It was concluded that high-risk postures were present in pump assembly workers diving into wells [69].

Manufacture of Leather and Related Products

There has been repeated use of the RULA method for the postural assessment of shoe factory workers. In some studies, it has been combined with the OWAS method and in others with the Nordic Musculoskeletal Questionnaire. In all the cases studied, negative results were obtained for some of the postures adopted [70,78,92].

These conclusions coincided with those obtained in a study on manual shoe-sewing workers. The RULA method was used together with a questionnaire. The need for postural correction was demonstrated; in some cases, it was required immediately [91].

Manufacture of Basic Pharmaceutical Products and Pharmaceutical Preparations

Two studies were developed in the pharmaceutical industry using the RULA method and the Nordic Questionnaire. One concluded that RULA was not a very successful method for assessing this type of industry. The other aimed to assess lumbar and neck discomfort [71,79].

Textile Manufacture

In the textile industry, two research studies were carried out using the RULA method and questionnaires. Approximately 380 workers participated. The results concluded that MSD was common. One of the studies found that the body areas suffering the greatest discomfort were the neck, knees and lumbar region [81,97]. Using the same ergonomic tools, Dianat et al. [87] also established that the neck and back were the body regions most affected in sewing machine workers. They also pointed to other areas such as the shoulders, wrists and hands.

Other authors also employed RULA in the textile industry along with the Nordic Musculoskeletal Questionnaire, or an adaptation of it. They assessed 566 workers in one study and 283 in the other. Both studies concluded that high levels of risk were present in their results and therefore there was a need to take corrective actions, in some cases immediately. They agreed that the affected body areas included the torso, neck and arms, amongst others [108,113].

Other assessments were carried out in industries located in Indonesia and Cambodia. In the first of these, a virtual space with a human model was used and four tasks were analysed: cutting, sewing, putting on buttons and finishing. The Posture Evaluation Index (PEI) was used, which includes the LBA, OWAS and RULA scores. The second was performed using interviews and RULA. In both cases, workers could develop musculoskeletal disorders [83,114].

Analysis was also carried out on people working in rug-fixing workshops. They usually performed their tasks squatting. Using a survey, it was possible to deduce the most affected body regions, and then to design a new work posture from this information. This posture was subsequently assessed with RULA, demonstrating it to be less harmful [125].

Other authors found a way to organise clothing assembly tasks at particular workstations. To do this, they assessed both productivity and ergonomics; RULA was used for the latter [99].

Using the same ergonomic tools, Dianat et al. [80] concluded from the studies described above that there is a high onset rate of musculoskeletal disorders among sewing workers.

Finally, several ergonomic studies have also been carried out in the batik cap industry. One demonstrated the emergence of MSD among the workers, and the other two determined new work postures for specific tasks that were less harmful $[82,88,98]$. 
Manufacture of Basic Metals

Garcia-Garcia et al. [95] used RULA and REBA along with virtual simulation to assess workers in a metal factory. Kushwaha and Kane [74] utilised the method to ergonomically assess two crane cabs (the usual one and a new design) in the steel industry. The new cab was designed with CATIA software and was shown to improve worker ergonomics.

Manufacture of Chemicals and Chemical Products

The Nordic Musculoskeletal Symptoms Questionnaire (NMSQ) and the RULA method were used to study ergonomics in chemical industry workers when performing various tasks. RULA showed that they were suffering from MSD. Automation and work modification [73] were proposed as a solution.

Repair and Installation of Machinery and Equipment

The risks that occur during the maintenance of a REHM V8 furnace were analysed using a modification of the NTP 330 method. The ergonomic risks were also contemplated using the RULA method and interviews. It was concluded that the ergonomic risks, amongst others, were detrimental to workers [86].

Manufacture of Electrical Equipment

At a transformer factory in Brazil, worker ergonomics were studied using RULA and a questionnaire. Risk factors were shown to be related to the posture adopted and the work rate. Immediate changes to the tasks [93] were required.

Manufacture of Paper and Paper Products

CATIA P33 V5R14 software was used to recreate the posture adopted by workers in a packaging business. RULA was used for the ergonomic assessment. Certain harmful postures were determined, mainly in tasks where heavy loads were lifted, or tasks which included bending [100].

Manufacture of Rubber and Plastic Products

In total, 25 rubber sheet manufacturing workers were ergonomically assessed using RULA, REBA and OWAS, specifically looking at nine9 different tasks. Most of the postures adopted were repeated continuously and the job was not particularly comfortable for the workers. High scores for these working postures [109] were determined according to the methods applied.

Manufacture of Wood, and Wood and Cork Products, Except Furniture; Manufacture of Articles Made from Wicker and Plaiting Materials

Several research studies were conducted on sawmill workers, using RULA in conjunction with other assessment methods and ergonomic tools. The objective was to compare the results using the different methods to find if there was any agreement among them [118,120,121].

Other

This section includes studies that are also within the scope of industry, but which cannot be included in any of the classification groups used.

Most of these studies were carried out in the past 17 years. The first one performed aimed to establish the QEC method action categories. To do this, several industry jobs were analysed using QEC and RULA, and then the results were compared [127]. RULA was also compared to other methods (OWAS and REBA) by analysing 301 worker postures in industries such as the electronics, steel, chemical and automotive industries, as well as in a hospital. OWAS and REBA ranked $21 \%$ of the postures in Categories 3 and 4, while RULA ranked 56\% of them [122]. This method was also compared to seven others by performing an ergonomic assessment of 567 industrial tasks. The results were 
shown to be different for the same work post depending on the method used. RULA determined a high risk for nearly $80 \%$ of the jobs [111].

Eswaramoorthi et al. [119] used RULA with CATIA V5 software to assess assembly line workers. This assessment led to changes in job design to reduce or eliminate waste, as these could cause an increase in the heavy physical burden on the worker. The method was also used in another assessment of this type, but in this case on a humanoid robot arm with similar postures to those adopted by a human. The goal was to assess the robot arm's configurations [112]. Related to the above, a method was developed allowing one to configure the manipulation of articulated robots which moved similarly to humans. RULA was used to analyse the coincidence between the robot and the human [110]. Continuing in the field of robotics, one study focused on the design and analysis of a system based on gesture control. The goal was to allow workers to control an industrial-type robot. The RULA [62] method was also used for its design.

Moreover, RULA was combined with other advanced tools to carry out new research. To improve industrial production, an ergonomic study was combined with virtual reality. The design of a cell was carried out to reduce worker fatigue [54]. Conversely, RULA was combined with Kinect to collect information on the movements made by workers during mounting and assembly tasks [72,103]. Likewise, an ergonomic assessment was performed using the DELMIA (Digital Enterprise Manufacturing Interactive Application) simulation tool for assembly tasks in the robotics industry. RULA determined the harmful postures and the necessary redesign of the work to improve them [85]. Finally, a system was developed using sensors placed on the workers' bodies. RULA was used by a computer in real time, displaying the results on a screen. When these were very harmful, acoustic and visual signals were initiated. It was concluded that this system, which showed the information to the worker, reduced the occurrence of MSD [101].

Rivero et al. [89] carried out an assessment of industrial and construction workers using RULA. They explained that increased productivity is closely linked to good worker ergonomics. Other authors also used it in conjunction with OSHA and the NIOSH equation. They concluded that rapid changes were required in $65 \%$ of the industrial tasks [84,94].

Baptista et al. [102] conducted three studies with three methods, including RULA. In total, 109 factory workers participated. The results showed that there were workers suffering from MSD, although no indications were presented. Finally, Yazdanirad et al. [61] also used three assessment methods to assess 210 people in three industries (the automotive, pharmaceutical and assembly industries). The results concluded that RULA was the most suitable method.

\subsubsection{Water Supply; Sewerage, Waste Management and Remediation Activities}

Table 6 presents a single study belonging to this category.

Table 6. Water supply; sewerage, waste management and remediation activities.

\begin{tabular}{cccc}
\hline Reference & Year & Country & Study Objective \\
\hline$[128]$ & 2015 & Turkey & $\begin{array}{c}\text { RULA and REBA assessment of } \\
\text { workers in waste collection. }\end{array}$ \\
\hline
\end{tabular}

Cakit [128] conducted a study to analyse waste collection workers. A programme was used to assess the postures adopted during loading and unloading. In addition, the RULA and REBA methods were used. They concluded the need for urgent changes in the postures adopted.

\subsubsection{Construction}

Table 7 presents studies conducted in the construction field using RULA. 
Table 7. Construction.

\begin{tabular}{cccr}
\hline Reference & Year & Country & Study Objective \\
\hline$[129]$ & 2019 & Canada & Development of a 3D system to simulate the working environment in the construction field. Use of RULA in \\
the ergonomic assessment.
\end{tabular}

Shanahan et al. [132] analysed the usefulness of three assessment methods (RULA, REBA and the Strain Index) when used in non-fixed tasks and comparing them with four psychophysical scales from Borg 10. Fourteen construction workers without MSD were followed up. They concluded that the best method for this type of task was the Strain Index.

Another study proposed a more accurate way of measuring the angles in the postures adopted by construction workers in order to use the RULA method [131].

Finally, Li et al. $[129,130]$ also focused on the field of construction. They developed a 3D system that allows one to simulate the working environment and perform an ergonomic assessment. They also applied REBA and RULA for the analysis.

3.1.6. Wholesale and Retail Trade; Repair of Motor Vehicles and Motorcycles

In this category, only three studies are presented (Table 8).

Table 8. Wholesale and retail trade; repair of motor vehicles and motorcycles.

\begin{tabular}{cccc}
\hline Reference & Year & Country & Study Objective \\
\hline$[133]$ & 2014 & Malaysia & Assessment using RULA, the modified Nordic Questionnaire and other tools on car repair mechanics. \\
\hline$[134]$ & 2017 & Italy & Assessment using RULA, REBA, the Strain Index and OCRA on clothing store vendors. \\
\hline$[135]$ & 2016 & Italy & Development of a portable and wireless tool based on the RULA method and the Strain Index for \\
postural assessment.
\end{tabular}

Wholesale and Retail Trade and Repair of Motor Vehicle and Motorcycles

Risk factors and the onset of MSD were studied in car repair mechanics. In total, 191 workers participated. The modified Nordic Questionnaire was used with RULA, in addition to other tools. Most workers were shown to have this type of disorder [133].

Retail Trade, Except Motor Vehicles and Motorcycles

Capodaglio [134] conducted an ergonomic study on 70 clothing store vendors. RULA, REBA, the Strain Index and OCRA were used. The results showed a high risk in the upper extremities for the postures adopted. Another study was carried out at supermarket check-outs. A tool was developed to carry out a postural assessment of the workers. It was a portable and wireless system based on RULA and the Strain Index. It allowed the assessment to be performed as the task was being undertaken [135].

\subsubsection{Transportation and Storage}

Table 9 contains the studies available in the Transportation and Storage category. 
Table 9. Transportation and storage.

\begin{tabular}{cccr}
\hline Reference & Year & Country & Study Objective \\
\hline$[136]$ & 2018 & Brazil & Assessment with RULA and a survey on dangerous goods drivers. \\
\hline$[137]$ & 2017 & France & Application of RULA and measurement of angles with sensors in material handling workers. \\
\hline$[138]$ & 2017 & China & Development of a new method based on the RULA method. \\
\hline$[139]$ & 2016 & Iran & Development of a new nozzle for fuel hoses and assessment with RULA of the people who used it. \\
\hline$[140]$ & 2016 & India & Assessment with RULA, REBA and other tools on industrial vehicle drivers. \\
\hline$[141]$ & 2016 & Cambodia & Assessment of the use of a new tool using RULA for storage in supermarkets. \\
\hline$[142]$ & 2015 & Saudi Arabia & Application of RULA and other tools on supermarket warehouse workers. \\
\hline$[143]$ & 2012 & Venezuela & Assessment with RULA and OCRA of workers of a transport company. \\
\hline$[144]$ & 2012 & USA & Assessment with RULA, REBA, PLIBEL and iLMM of bus drivers responsible for handling wheelchairs. \\
\hline$[145]$ & 2008 & Slovenia & Application of goniometry and OWAS, RULA and CORLETT on car drivers. \\
\hline$[146]$ & 2005 & United Kingdom & RULA and OWAS were applied in addition to other tools on forklift drivers. \\
\hline$[147]$ & 2003 & Italy & RULA assessment of garbage truck and road cleaning drivers.
\end{tabular}

Land Transport and Transport via Pipelines

The RULA method was used in various studies to analyse drivers of different vehicles, such as garbage trucks and road-cleaning trucks. In total, 77 workers participated. The study concluded that the neck was the most affected area. The scores obtained varied depending on whether an adjustable seat was used [147]. Drivers of dangerous goods vehicles also suffered discomfort in the neck region, as well as in the feet, ankles, hands, etc. According to RULA, immediate changes to the tasks were required [136]. Similarly, car drivers were assessed, but this time RULA was used along with other methods such as OWAS and CORLETT. Goniometry was applied on some workers. The results showed different levels of discomfort in various parts of the body [145]. The method was used together with OCRA to assess workers in five transport company posts. In addition, a group interview was carried out. RULA demonstrated action Levels 1 and 2 [143].

Hoy et al. [146] studied the vibrations and postures to which forklift drivers were exposed. RULA, OWAS and a questionnaire were applied, and the vibrations were measured. The posture test results showed frequent lumbar discomfort. The highest risk level postures were those comprising a bent or twisted torso.

Another such study focused on wheelchair-support bus drivers. The assessment involved four workers and one passenger. Three different wheelchairs were used. The RULA, REBA, PLIBEL and iLMM methods were employed. High-level risks were determined during this task [144].

Balaji and Alphin [140] focused on drivers of industrial vehicles. Their objective was to optimise the worker's area in the vehicle in order to reduce discomfort from the postures adopted. The software analysis was performed using RULA and REBA. Nearly half of the workers performed the task at a high-risk level. The areas most affected were the arm, wrist and torso.

Lastly, a new type of nozzle was developed for fuel refilling hoses. One hundred people were assessed using RULA while putting fuel in their vehicles. The postures were shown to be less harmful with the new design [139].

Warehousing and Support Activities for Transportation

In total, 92 workers from a supermarket warehouse were ergonomically assessed, specifically in two tasks-lifting boxes and pulling them. RULA was used in conjunction with other tools. Lifting the boxes affected the workers' lower back, while the other task affected the lower arm and wrist [142]. Using the same method in the same workplace, they assessed the effect caused by a new storage tool. They concluded that it allowed for better work completion and resulted in less back and shoulder risks [141].

Finally, material handling workers were assessed. Sensors capable of measuring angles during a work task were used and, from these data, RULA was applied. The results showed high levels of risk in the postures adopted [137]. 


\section{Air Transport}

Some authors performed a study in which a new RULA method was developed. This allowed astronauts to be posturally assessed [138].

\subsubsection{Accommodation and Food Service Activities}

Three studies are differentiated in this field of knowledge (Table 10).

Table 10. Accommodation and food service activities.

\begin{tabular}{cccc}
\hline Reference & Year & Country & Study Objective \\
\hline$[148]$ & 2018 & Brazil & Use of a survey and REBA, RULA and OWAS methods in industrial kitchen workers. \\
\hline$[149]$ & 2014 & China & Application of OWAS, RULA and the NIOSH equation in cooks at a Chinese restaurant. \\
\hline$[150]$ & 2005 & Canada & Use of 4 ergonomic tools, including RULA in pub workers. \\
\hline
\end{tabular}

Workers in an industrial kitchen, chefs at a Chinese restaurant and pub workers were assessed. RULA was used in all of these along with other ergonomic methods or tools. In the first case, RULA obtained more harmful results than for the other methods applied. The second showed that repetitive actions were performed on the upper extremities. The third concluded that very harmful tasks existed that required corrective actions [148-150].

\subsubsection{Information and Communication}

Table 11 is composed of the different studies that have been carried out in the area of Information and Communication.

Table 11. Information and communication.

\begin{tabular}{|c|c|c|c|}
\hline Reference & Year & Country & Study Objective \\
\hline [151] & 2019 & Turkey & $\begin{array}{l}\text { Testing using RULA and other tools of the effectiveness of ergonomic training to people who make regular } \\
\text { use of the computer. }\end{array}$ \\
\hline [152] & 2014 & Israel & $\begin{array}{l}\text { Application of the RULA method and a modification of it (mRULA) in computer workers, to check if } \\
\text { mRULA was valid. }\end{array}$ \\
\hline [153] & 2012 & Iran & $\begin{array}{c}\text { Testing using RULA of whether there was an improvement or not in the ergonomic results in VDT workers } \\
\text { after training. }\end{array}$ \\
\hline [156] & 2003 & United Kingdom & Use of RULA in workers who used the computer and were visually impaired. \\
\hline [157] & 2002 & Turkey & $\begin{array}{c}\text { The benefits of ergonomic training and physiotherapy sessions in VDT operators were studied. Use of RULA } \\
\text { and other tools. }\end{array}$ \\
\hline [158] & 1999 & USA & Use of RULA in workers who entered data with VDT screens and others that classified and sorted documents. \\
\hline [159] & 1998 & Australia & Application of RULA and surface electromyography on computer workers. \\
\hline
\end{tabular}

Several studies have been carried out on people who work regularly on a computer. One of these studies investigated whether the position where the mouse was placed with respect to the keyboard influenced the arm and shoulder postures adopted. RULA and surface electromyography were used. Some results showed that the position taken by right-handed people was less damaging if the number keyboard was not used [159]. Another similar analysis was performed on 10 workers who were also visually impaired. Harmful postures were identified for all the participants, and several recommendations [156] were made. Ekinci et al. [151] carried out an assessment very similar to the previous cases, using other tools in addition to RULA. The objective was to check the effectiveness of pre-use ergonomic computer training. Ergonomic risk was shown to decrease as a result. One of the workers carrying out this same task was followed up. They indicated discomfort in the neck and upper right extremity. They received physiotherapy sessions and ergonomic intervention, after which RULA indicated an improvement in the results [154].

Other authors used RULA [158] to assess workers carrying out two specific tasks, one based on entering data using VDT (Visual Display Terminal) screens and another on document classification 
and sorting. The results showed that the first task required further assessment. The second had to be modified after identifying harmful postures. Another group of VDT workers had the ergonomic training they received assessed using the method. The results improved after this, reducing the action levels [153]. To this end, RULA was used in conjunction with the Visual Analog Scale (VAS) to test the benefits of ergonomic training and physiotherapy sessions. VDT operators from the Software Corporation participated. It was observed that the methods were beneficial as they decreased the risk factors and the development of musculoskeletal disorders [157].

Other authors ergonomically assessed workers at a technology company, focusing on programming, management, administration and marketing tasks. RULA deduced high action levels with no risk-free postures [155]. Lastly in this area, the RULA method was applied, along with a modified version of it (mRULA), on 29 people working in computer science. The goal was to know if mRULA was valid for ergonomic assessment. They concluded that it could be used, and that it was only necessary to make an observation [152].

\subsubsection{Financial and Insurance Activities}

Table 12 encompasses a single research study.

Table 12. Financial and insurance activities.

\begin{tabular}{cccc}
\hline Reference & Year & Country & Study Objective \\
\hline$[160]$ & 2012 & Brazil & $\begin{array}{c}\text { Application of the RULA method on workers in the } \\
\text { financial department of a hospital. }\end{array}$ \\
\hline
\end{tabular}

An ergonomic study was carried out in the financial department of a hospital using the RULA method. The results showed the need for ergonomic actions. This could reduce the grounds for absenteeism due to work-related accidents and increase well-being at work [160].

\subsubsection{Professional, Scientific and Technical Activities}

Publications relating to this category are presented below (Table 13).

Table 13. Professional, scientific and technical activities.

\begin{tabular}{cccc}
\hline Reference & Year & Country & Study Objective \\
\hline$[161]$ & 2016 & Spain & Application of OWAS and other tools to evaluate veterinarians. \\
\hline$[162]$ & 2008 & China & $\begin{array}{r}\text { Ergonomic analysis using software based on the RULA method of } \\
\text { people who perform their work on desktops. }\end{array}$ \\
\hline
\end{tabular}

Other Professional, Scientific and Technical Activities

A study was carried out to establish a procedure for product design managers to perform an ergonomic assessment at the start of the design. This was developed for work carried out on desktops. To this end, information on the movement of workers was collected and a digital human model was created. Software incorporating the RULA method was used to perform the ergonomic analysis [162].

Veterinary Activities

The work of 12 veterinarians was assessed while performing four different tasks. Several tools were used, including a modification of RULA, to assess the wrist. It was concluded that, of the four tasks, only the posture adopted for suturing was not detrimental to the wrist [161].

\subsubsection{Administrative and Support Service Activities}

In this field of knowledge, 12 studies have been analysed (Table 14). 
Table 14. Administrative and support service activities.

\begin{tabular}{|c|c|c|c|}
\hline Reference & Year & Country & Study Objective \\
\hline [163] & 2019 & Iran & $\begin{array}{l}\text { Assessment of the benefits of an ergonomic programme performed on office workers in a petrochemical } \\
\text { company using a questionnaire and RULA. }\end{array}$ \\
\hline [164] & 2017 & Netherlands & To verify an upper extremity assessment questionnaire, with the help of RULA. \\
\hline [165] & 2017 & Brazil & Application of ROSA, RULA and the Maastricht questionnaire to assess office workers. \\
\hline [166] & 2016 & Philippines & Use of the Standardized Nordic Questionnaire, and the RULA and REBA methods on cleaning workers. \\
\hline [167] & 2015 & USA & Application of RULA and a lighting study on office workers. \\
\hline [169] & 2015 & Brazil & RULA, along with other methods and questionnaires, was applied to office workers. \\
\hline [170] & 2014 & Portugal & RULA was applied to administrative workers. \\
\hline [171] & 2014 & Turkey & $\begin{array}{l}\text { The effectiveness of web ergonomic training for office workers was assessed. The RULA method and surveys } \\
\text { were used. }\end{array}$ \\
\hline [172] & 2012 & Australia & Use of ManTRA, QEC and RULA on cleaning workers. \\
\hline
\end{tabular}

Building Services and Landscape Activities

Two studies were carried out on cleaning workers using the RULA method. The first was used in conjunction with the REBA method and the Standardized Nordic Questionnaire. The results indicated risks ranging from medium to very high [166]. The second also made use of the Manual Task Risk Assessment (ManTRA) and QEC and the cleaning task was assessed. The results showed that the staff developed musculoskeletal disorders [172].

\section{Office Administration, Office Support and Other Business Support Activities}

Several research studies were conducted on the risks of MSD for office workers. One of these focused on computer staff. The workers were divided into two groups, one of which contained workers already suffering from discomfort. The ROSA (Rapid Office Strain Assessment), RULA and Maastricht questionnaire methods were used. RULA indicated worse scores for workers suffering discomfort [165]. Two similar studies were performed (one of which was determined with RULA) showing that more than half the workers suffered from musculoskeletal disorders and that the most injured areas of the body were the back and upper limbs. The other study proposed corrective actions for the work carried out $[169,174]$. Administrative workers were ergonomically studied in the same way. In addition to using RULA, measurements were taken of the workers and the office furniture. The study concluded that the subjects were developing MSD. Corrective actions were necessary over the short term [170].

Two further studies were carried out with RULA using an intervention group and a control group. In one of them, two groups were created containing 100 workers, and lighting data and information were collected. It was determined that the use of adjustable lights improved both the ergonomics and vision while the tasks were carried out [167]. In the other study, the intervention group used a particular keyboard, mouse and touchscreen. RULA showed a decrease in harmful upper limb postures although this worsened for the hands [168].

Several works were also carried out, the objective of which was to assess ergonomic programmes. One of them was performed in Iran on office workers in a petrochemical business. A questionnaire and the RULA method were used for the assessment. Improvements were made to the postures affecting the neck, shoulders, upper back and lumbar area thanks to the ergonomic programme [163]. With the same purpose in mind, Taieb-Maimon et al. [173] assessed three groups of workers who used computers in offices, one the control group and two that had received different types of training. Workers were assessed with RULA before, during and after the training. It was observed that the two groups with training improved their postures in a short period of time. Dalkilinc and Kayihan [171] also demonstrated that ergonomic training improved the postures adopted by office workers; they used RULA and surveys. In this case, it was web training. 
Finally, in this field of knowledge, Cavalini et al. [164] verified an upper extremity assessment questionnaire called the Upper Extremity Work Demand (UEWD-R). The assessment was carried out using RULA with the help of office workers who used computers. The results indicated that the questionnaire was valid for assessing postural load on upper extremities.

\subsubsection{Public Administration and Defence; Compulsory Social Security}

Table 15 presents the research developed in this field.

Table 15. Public administration and defence; compulsory social security.

\begin{tabular}{cccc}
\hline Reference & Year & Country & Study Objective \\
\hline$[175]$ & 2017 & South Korea & Application of OWAS, RULA and REBA on soldiers. \\
\hline$[176]$ & 2010 & USA & $\begin{array}{c}\text { Application of REBA, RULA and the NIOSH equation on } \\
\text { firefighters and emergency physicians. }\end{array}$ \\
\hline
\end{tabular}

Nam et al. [175] assessed the postural load on soldiers when cleaning cannons in two different ways: manually and with an automated tool. OWAS, RULA and REBA were applied. They concluded that there was a lower risk (Level 2) when using the tool than with manual cleaning (Level 4). Another assessment of this type was developed for firefighters and emergency physicians. RULA, REBA and the NIOSH equation were used. The results showed high risks, indicating the need for corrective action [176].

\subsubsection{Education}

Table 16 consists of 12 studies developed in education.

Table 16. Education.

\begin{tabular}{|c|c|c|c|}
\hline Reference & Year & Country & Study Objective \\
\hline [177] & 2018 & South Africa & Use of RULA and a questionnaire on students using the computer. \\
\hline [178] & 2018 & Philippines & Application of RULA and REBA on students in a chemistry laboratory. \\
\hline [180] & 2014 & Australia & $\begin{array}{l}\text { Ergonomic assessment with RULA of children using ICT (Information and Communications Technology) to } \\
\text { ascertain if the assessor's experience is relevant in this method. }\end{array}$ \\
\hline [181] & 2014 & Iran & $\begin{array}{l}\text { Use of the Nordic Musculoskeletal Questionnaire, the RULA method and other methods as well as } \\
\text { interviews on people who used computers at two universities. }\end{array}$ \\
\hline [182] & 2014 & Malaysia & The use of RULA and other tools on elementary school students. \\
\hline [183] & 2012 & Iran & Assessing a training programme using RULA and other tools on university workers using computers. \\
\hline [184] & 2012 & Malaysia & Application of a questionnaire, REBA and RULA on students between 13 and 15 years old. \\
\hline [185] & 2011 & Indonesia & $\begin{array}{l}\text { Use of a virtual environment for ergonomic analysis of a bicycle. PEI was used, containing methods such } \\
\text { as RULA. }\end{array}$ \\
\hline
\end{tabular}

Breen et al. [188] and Kelly et al. [187] used RULA and other tools to study the postures adopted by students on the computer. Some authors focused on primary schools and others on high schools. They concluded that about $60 \%$ of the postures belonged to action Level 2. Sellschop et al. [177,179] provided ergonomic training to students with the same characteristics. They assessed effectiveness using two groups (the intervention and control groups) with the same method and other tools. In the intervention group, the risk decreased according to RULA, with action Level 4 disappearing. Other authors found that the assessor's experience of using RULA and task observation was not relevant. They demonstrated this by assessing children while they took part in ICT. The study was performed by two groups of assessors, one of them experienced in applying the method [180]. 
Some authors $[181,186]$ ergonomically analysed students at the university level, also while using computers. Two studies are differentiated, one using the RULA method and the other a modification of it (mRULA) in addition to other tools. It was shown that, at an engineering university, $30.8 \%$ of participants were exposed to a Level 3 risk. In medicine, $42.9 \%$ were exposed to a Level 2 risk. On the other hand, when employed at the Qazyin University of Medical Sciences on workers using the computer, it was intended to assess a training programme. This was done in stages, through a control group and an intervention group. RULA, VAS and the Nordic Questionnaire were used. The intervention group improved. The programme proved beneficial to the workers [183].

Furthermore, in the field of education, other ergonomic analyses were carried out using RULA and other tools. They focused on students at different levels. In some cases, harmful postures were adopted due to, among other causes, the furniture used. New furniture designs were required [178,182]. Students aged between 13 and 15 were also assessed in a total of 104 positions. It was concluded that the 13-year-olds were more at risk [184].

Finally, other authors used a virtual environment to perform an ergonomic analysis on a folding bike. This was designed at the University of Indonesia. RULA was used along with other methods. The goal was to obtain the best design, which was completed when the handlebars were $32 \mathrm{~cm}$ high and the saddle at $83 \mathrm{~cm}$ [185].

\subsubsection{Human Health and Social Work Activities}

Table 17 presents the studies according to the "Human health and social work activities" category.

Table 17. Human health and social work activities.

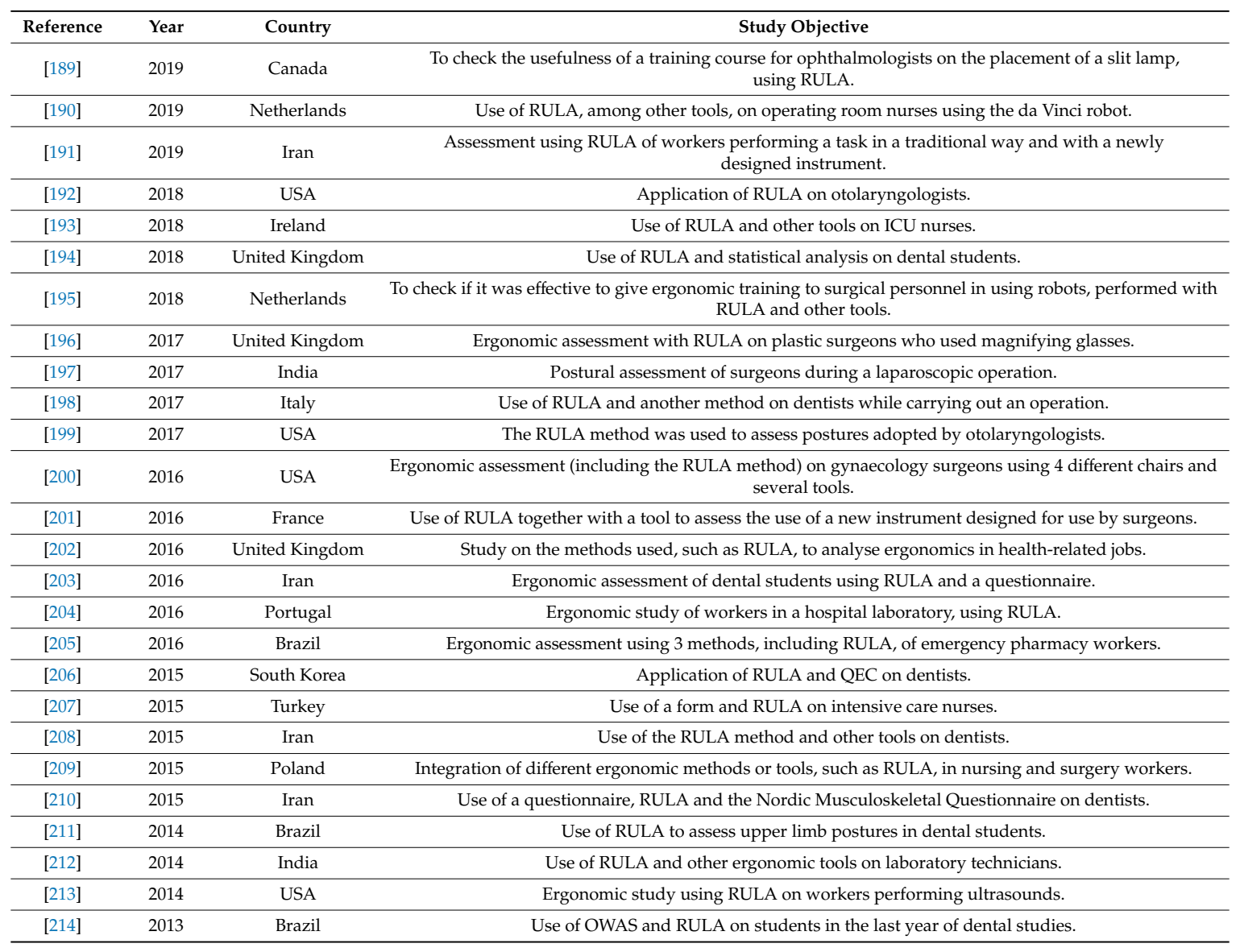


Table 17. Cont.

\begin{tabular}{cccr}
\hline Reference & Year & Country & Study Objective \\
\hline$[215]$ & 2013 & USA & Ergonomic study using RULA and other ergonomic tools on surgeons manipulating a robot. \\
\hline$[216]$ & 2013 & South Korea & Use of REBA, RULA and the Strain Index on dental hygienists. \\
\hline$[217]$ & 2012 & USA & Ergonomic analysis using RULA, amongst other tools, on office-based surgery workers. \\
\hline$[218]$ & 2011 & USA & Using a virtual reality simulator on surgeons performing a laparoscopic cholecystectomy. Ergonomic \\
assessment with RULA.
\end{tabular}

This field is divided into different specialties to show the available studies in a more ordered fashion.

\section{- Ophthalmology}

Ratzlaff et al. [189] tested the usefulness of an ergonomic training course given to 10 ophthalmologists. They focused on a task that consisted of positioning a slit lamp. It was assessed before and after training, using RULA applied with software. Risk levels were shown to be lower after training.

- Radiology

In the United Kingdom, mammogram radiologists were ergonomically assessed. Three work posts were analysed, one for digital mammograms, one for film mammograms and the third for both. The RULA method was used. It was determined that no more MSDs developed as a result of performing the mammograms digitally [222].

- $\quad$ Nursing

Sezgin and Esin [207] evaluated 1,515 intensive care nurses. They mainly used the RULA method. They showed that the hardest-hit areas of the body were the back and legs. They also concluded that the scores for this method were lowered by giving the Ergonomic Risk Management Programme (ERMP) to workers [193].

Sung et al. [219] decided to use an armrest and mirror to observe the tubes after each blood test. These proposals reduced the RULA score from 7 to 2 . Therefore, the postures of the workers improved, mainly in the neck and shoulders.

As a last study, Garosi et al. [191] designed and developed a new instrument for a nursing task that used to be done manually. According to RULA, the level of risk decreased from 3 to 2 in the upper extremities when using this new tool.

- Otolaryngology

Goyil et al. [192,199] analysed the postures adopted by the otolaryngologists when the patient was placed in position (sitting or lying on their back). The RULA method was used. Higher risk levels were determined for sitting patients.

- Ultrasounds

Workers performing ultrasounds were assessed because they often suffer from musculoskeletal discomfort. RULA was used on five participants and on 24 ultrasounds; other parameters were also taken into account. The results showed awkward postures for the upper limbs [213]. 


\section{- $\quad$ Laboratory}

Some authors found that lab workers in hospitals developed MSD from performing their tasks. In these studies, they applied RULA, sometimes with other methods or tools [204,212].

- $\quad$ Surgery

The use of robots in surgery does not always lead to correct postures in the workers. Several authors assessed surgical personnel during their work using RULA and other tools. They found detrimental results and the need to modify the tasks $[190,215]$. One solution could be to provide ergonomic training to workers who perform surgery with robots. According to RULA, this improved the levels of risk [195]. The use of robot in other cases led to ergonomic improvements. One of these was when performing endoscopies. Surgeons obtained lower RULA scores when using robots than when performing the operation manually [224].

Other authors focused their studies (using the RULA method) on surgeons performing laparoscopies. They showed that there was a risk regarding the postures the surgeons developed [197]. In some cases, they combined these studies with the use of new technologies. For example, Youssed et al. [218] used a virtual reality simulator in this type of study, whereas Sanchez-Margallo et al. [221] used a glove called a CyberGlove (R). This glove allowed one to measure the movements made by the wrist, which can then be applied to an adapted RULA method. Bensignor et al. [201] designed a robotic needle holder for this type of surgery. Using RULA, they demonstrated that surgeon's postures were less harmful than when performing the technique in the traditional way.

Other ergonomic analyses were performed on surgeons carrying out various tasks. Li et al. [196] used RULA to assess plastic surgeons who used magnifying glasses, and who suffered discomfort in the upper extremities. They indicated that modifying the height of the table or the distance of the magnifying glass from the workplace could lessen these problems. Person et al. [225] used an optoelectronic system to take posture data and obtain results using a modified RULA. They found harmful results mainly at the wrist. Hermandon and Choi [217] agreed that the wrist was one of the hardest-hit areas. They used RULA and other tools on office-based surgery (OBS) workers. They concluded that these workers were at high risk of musculoskeletal disorders. In addition, they highlighted other areas of the body that were harmed such as the arms, shoulder, neck and back.

Other authors assessed surgeons' postures using RULA when they performed the same procedure in different ways. For example, Statham et al. [220] focused on laryngeal microsurgery surgeons. They assessed them while performing the task adopting three different postures, one with the arms unsupported and the other two with different supports. They deduced the levels of risk to which the surgeons were exposed. Singh et al. [200] assessed gynaecology surgeons using four different chairs. They determined a medium-to-high risk in the neck and shoulders. They showed that the chairs did not influence the scores.

Finally, some authors presented the idea of integrating different ergonomic methods and tools to assess nursing and surgery workers. OWAS, REBA, RULA and NIOSH were used, amongst other methods [209].

\section{- $\quad$ Dentistry}

Several authors focused on ergonomically assessing dental students while they were doing their internships. This was done using RULA, sometimes together with other methods or questionnaires. They concluded that there was a high level of risk regarding musculoskeletal disorders [203,211,214]. Ergonomic improvements in this area showed that using a Bambach Saddle armchair resulted in lower risk than when using a conventional chair [223], and that using magnifying glasses was beneficial for adopting lower-risk postures [194].

This type of study was also conducted on dentists to assess their postures. RULA was used in conjunction with other methods in most cases. Marcon et al. [198] compared the difference between 
using a magnifying glass, a microscope or not using anything at all during operations. They showed that using a microscope led to more harmful postures. In addition, these dentists are usually harmed by the postures they adopt during their tasks. Therefore, it is necessary to establish changes, some of which are required immediately. The most affected parts of the body are the lumbar region and neck [206]. This coincides with that determined by Tirgar et al. [208], although they added that another area affected was the shoulders, as inferred by Rafie et al. [210].

To conclude this group, the ergonomics of dental hygienists were also studied. They used RULA, REBA and the Strain Index. It was concluded that the postures the hygienists adopted contributed to the onset of musculoskeletal disorders [216].

- $\quad$ Other

An ergonomic assessment of workers in an emergency pharmacy was carried out using three methods, including RULA. This led to some improvements in their work [205]. Another series of improvements was made for women workers in the biomedical field. An intervention was carried out based on changes to the workplace and recommendations. According to RULA, this was beneficial as it led to lower scores for more than half of the postures [226]. Finally, methods for analysing ergonomics in health-related jobs were studied. It was concluded that RULA could be used to attain more accurate results [202].

\subsubsection{Arts, Entertainment and Recreation}

Table 18 includes only three studies.

Table 18. Arts, entertainment and recreation.

\begin{tabular}{cccc}
\hline Reference & Year & Country & Study Objective \\
\hline$[227]$ & 2013 & India & $\begin{array}{r}\text { The modified Nordic Questionnaire, REBA and RULA were } \\
\text { applied to potters and sculptors. }\end{array}$ \\
\hline$[228]$ & 2011 & Israel & RULA and questionnaires were used on orchestral musicians. \\
\hline$[229]$ & 2010 & India & RULA, REBA, OVAKO, OCRA and the Strain Index were \\
applied to craft workers.
\end{tabular}

In the field of music, some authors demonstrated, with RULA and other tools, that musicians often suffer MSD mainly in the upper extremities. The risk is higher in those who play string instruments [228]. The development of such disorders was also confirmed in potters, sculptors and craft workers in India. They made use of RULA and other assessment methods. For all cases, harmful postures were deduced as well as the need to make changes to avoid them, immediately for the crafts workers [227,229].

\subsubsection{Other Service Activities}

Only three studies are presented in this category as well (Table 19).

Table 19. Other service activities.

\begin{tabular}{cccc}
\hline Reference & Year & Country & Study Objective \\
\hline$[230]$ & 2017 & USA & Use of a survey and the RULA method on tattooists. \\
\hline$[231]$ & 2015 & India & REBA, RULA and OCRA were used on bicycle repair workers. \\
\hline$[232]$ & 2011 & Portugal & An ergonomic study using RULA and QEC was conducted on \\
workers from four spas.
\end{tabular}


Repair of Computers, and Personal and Household Goods

An ergonomic assessment was carried out on bicycle repair workers. The RULA, REBA and OCRA methods were used, along with other parameter measurement. The tasks assessed were shown to be at a high-risk level, and that immediate improvement actions were required [231].

Other Personal Service Activities

Some authors focused on spa workers, with the aim of preventing them from developing MSD during three of their tasks. An assessment was carried out with RULA and QEC. The results showed that ergonomic information and training would improve the postures adopted [232]. A similar study, using only RULA and a survey, was conducted on tattooists. It was concluded that $71 \%$ of the postures adopted had a high level of risk and therefore urgent corrective measures were needed [230].

3.1.18. Activities of Households as Employers; Undifferentiated Goods- and Services-Producing Activities of Households for Own Use

Table 20 summarises the publications in this category.

Table 20. Activities of households as employers; undifferentiated goods-and services-producing activities of households for own use.

\begin{tabular}{cccr}
\hline Reference & Year & Country & Study Objective \\
\hline$[233]$ & 2016 & Ecuador & $\begin{array}{r}\text { Assessment of people in wheelchairs who performed some } \\
\text { domestic or work activity, using the RULA method and MAPFRE. }\end{array}$ \\
\hline [234] & 2012 & Italy & $\begin{array}{r}5 \text { ergonomic methods or tools were used, including RULA, } \\
\text { on people performing household chores. }\end{array}$ \\
\hline
\end{tabular}

Domestic workers are also exposed to the onset of musculoskeletal disorders, although, according to Apostoli et al. [234], at a medium or low level. This was deduced by research in which RULA and other assessment methods or tools were applied. Another similar study was carried out using the RULA and MAPFRE methods, but in this case the workers were in wheelchairs. It was inferred that there were risks caused by the postures that had to be adopted in the chair in order to carry out the tasks [233].

\subsubsection{Other Areas Not Previously Included}

Finally, a category (Table 21) is presented that is not covered by the classification used but has applications that cannot be included in the above fields of knowledge. 
Table 21. Other scopes not previously included.

\begin{tabular}{|c|c|c|c|}
\hline Reference & Year & Country & Study Objective \\
\hline [235] & 2019 & Ecuador & New way to perform ergonomic analysis using the Kinect V2 sensor together with the RULA method. \\
\hline [236] & 2018 & Brazil & RULA and the deformation rate (SI) were studied, and the analysis of various jobs was carried out. \\
\hline [238] & 2018 & Malaysia & Research to compare the RULA method with the RULA-Kinect system. \\
\hline [239] & 2018 & Thailand & Ergonomic study using a questionnaire and the RULA method on people who use mobile phones. \\
\hline [240] & 2017 & France & A study using Kinect with the RULA method. \\
\hline [242] & 2017 & Italy & Development of a software called K2RULA. \\
\hline [243] & 2017 & South Korea & $\begin{array}{l}\text { Use of RULA in conjunction with Quick Rating (QRating) to assess people making gestures } \\
\text { while communicating. }\end{array}$ \\
\hline [244] & 2016 & Australia & Using sensors, including Kinect for the RULA application. \\
\hline [245] & 2015 & Sweden & Ergonomic assessment with RULA on children while they are using ICT devices. \\
\hline [249] & 2014 & Taiwan & Use of RULA on workers at a gas bottle company. \\
\hline [250] & 2013 & South Korea & Attempt to adopt gestures for virtual environment commands. RULA was used in the analysis. \\
\hline [251] & 2012 & Ireland & Employing RULA on children who are computer users. \\
\hline [252] & 2011 & Germany & Adapts the RULA method with Virtual Human to control human movements. \\
\hline [253] & 2011 & Portugal & Development of a semi-automatic system with two video cameras and RULA. \\
\hline [254] & 2011 & Portugal & Application of RULA and OCRA on workers using machines and other equipment. \\
\hline [255] & 2010 & Portugal & $\begin{array}{c}\text { Development of a semi-automatic system for ergonomic assessment using RULA and two } \\
\text { synchronised cameras. }\end{array}$ \\
\hline [256] & 2009 & Italy & Assessment performed with several methods, including RULA. \\
\hline
\end{tabular}

The different studies available are divided into groups according to the topic covered:

\section{- $\quad$ Sensors}

The Kinect sensor has been used in several studies together with the RULA method for ergonomic analysis. Some of them have compared the results by performing the assessment without the sensor and were similar. With Kinect, you can reduce the assessment time or subjectivity with professional analysis $[235,244]$.

- Use of mobile phones and computers

Some authors assessed people who sent SMS using their mobile phones. They used a questionnaire and the RULA method. The latter exposed a risk Level 3 for the right and left area of the body, so modifications [239] were required. Employing the same method, other authors assessed the postures of children using computers or other ICT devices. They deduced risk categories of Level 2 or higher for the latter. In the case of computers, it was inferred that the RULA method was not recommended for applying to girls under eight years of age [245,251].

- $\quad$ Methods

Can and Figlali [241] developed a new assessment method from RULA, called ARULA (Advanced RULA). This was characterised as improving the advantages of the initial method, such as its high pre-observation time, assessment, etc.

One assessment was carried out using various methods such as the State of Washington method, OCRA, RULA, the Strain Index, etc. A high or very high level of risk for the upper limbs [256] was obtained with all. Two of the above methods, the Strain Index and RULA, were also studied from the perspective of validity, reliability, etc. The analysis of various jobs that included static 
positions or repetitive tasks was carried out, concluding that training was necessary to apply the [236] methods. Finally, a study was conducted on perceived discomfort in the different postures of the upper extremities. The RULA method [248] was used.

- Technological Evolution

Technology was used to apply the RULA method in several studies. Manghisi et al. [242] developed software called K2RULA capable of assessing workers during the task or with subsequent analysis. Goncalves and Fernandes $[253,255]$ developed a semi-automatic system for performing ergonomic assessments using the RULA method. It was based on two synchronised video recording cameras for observing the worker's tasks. From these recordings, RULA automatically calculated the scores, obtaining the action level for each of the observations. Plantard et al. [246] developed a method for performing ergonomic assessments using a virtual mannequin and RULA scores. They noted that the results of this new method coincided with those that had actually been obtained. Finally, Schlette and Rossmann [252] adapted the RULA method with Virtual Human in order to control human movements. The goal was to control the movements of a humanoid robot that are similar to those performed by a human.

- Gestures

One study used RULA in conjunction with another method called Quick Rating (QRating) to ergonomically assess people who made typical gestures when communicating. Physical discomfort during these gestures should be controlled [243].

In another study, gestures were required for 18 commands used in the movement of objects in a virtual environment. To do this, they were determined using Korean sign language and others created by the user. All these gestures were analysed and the RULA method [250] was used for this purpose.

- Other works

Razavi and Behbudi [247] ergonomically analysed box office workers with the RULA method, following the adoption of a series of improvements. It was concluded that there was a reduced level of risk. The same type of study was carried out on workers at a gas bottle company. It determined the existence of postures with an action Level 3 risk, and the need for changes in a short period of time [249]. It was also carried out on workers who used machines and other equipment during their work. Anthropometric information and the OCRA method were also used [254].

On the other hand, Ward et al. [257] used RULA to assess the ergonomics of postures adopted in the use of biometric devices (fingerprints and veins on the palm of the hand). They concluded that the positions in which they were placed (angles and heights) influenced the postures adopted. McGorry and Lin [258] studied the influence on grip strength of the orientation and placement (height and distance) of tool handles. They used RULA to carry out an ergonomic assessment.

Finally, several authors developed two assessment methods, one that considered frequent and harmful postures and the other the time. An assessment was made, using these methods and a modified RULA method, of the postures adopted by a group of people. They deduced that there was no coincidence between the methods [259].

\subsection{Country-by-Country Ranking}

The revised applications are also classified according to their location, taking into account the fields of knowledge (Figure 5).

There are 34 countries where the RULA method has been used. The USA stands out with 23 studies, followed by Iran with 21, Malaysia with 17, India with 16, Portugal with 15, Brazil with 12 and Canada and the United Kingdom with 11. All other countries have 10 or fewer research studies. Eight locations have a single publication: Saudi Arabia, Japan, Mexico, Poland, Slovenia, Sweden, Tunisia and Venezuela (Figure 5). 
In addition to the USA having the largest number of studies, it is also the country where the most knowledge categories have been covered. This comprises a total of 10 areas. "Human health and social work activities" stand out with nine studies, followed by "Manufacturing" with three (Figure 5). Both categories match the ones that have the most published studies at the general level (Figure 4 and Table 2).

The places following the USA are Turkey, Italy, Iran, India and Brazil, with seven different locations. In all of them, except Italy, the largest number of publications also corresponds to "Manufacturing". Iran stands out with 11 studies in this category.

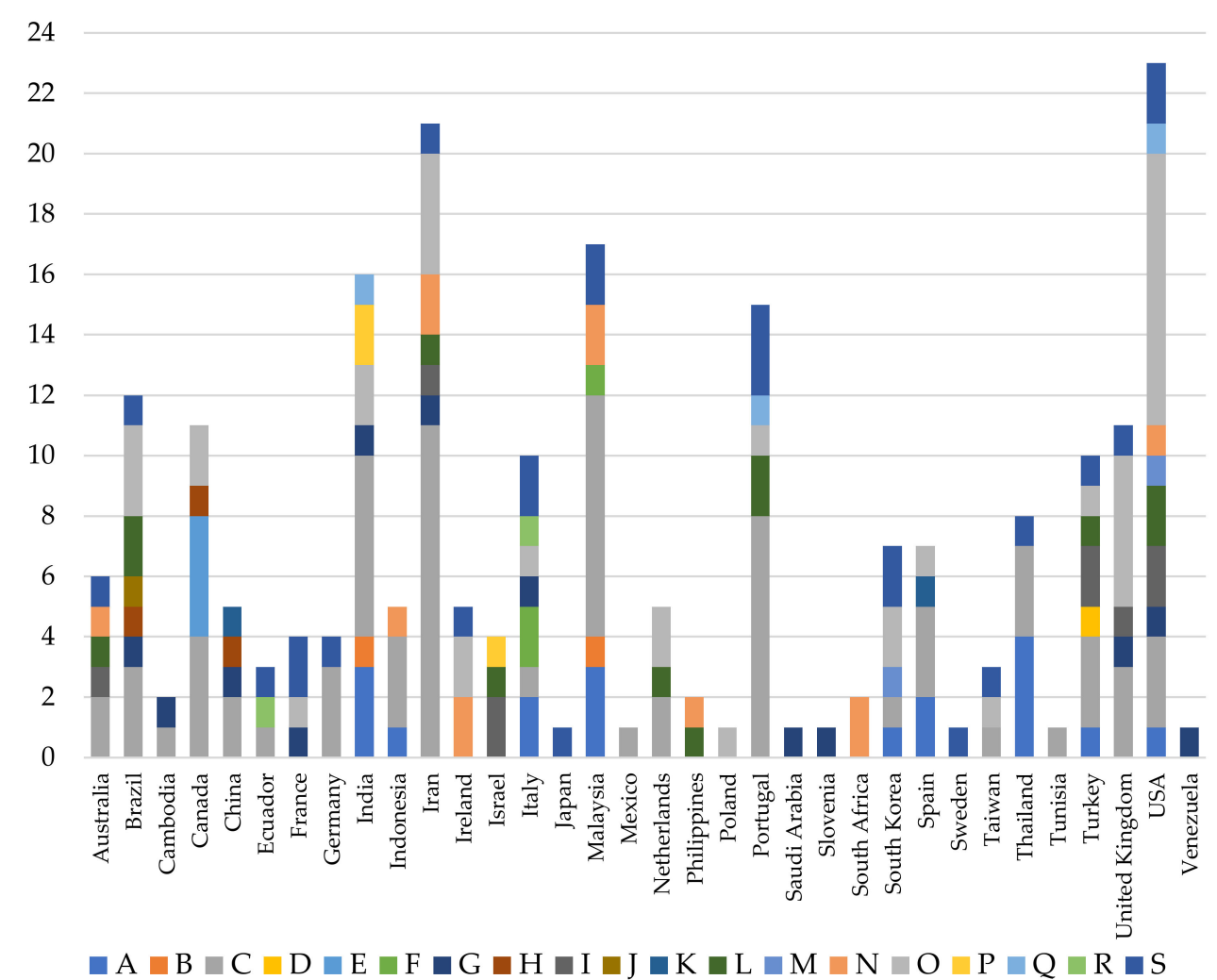

Figure 5. Number of studies classified by knowledge categories and countries: Agriculture, forestry and fishing (A); Mining and quarrying (B); Manufacturing (C); Water supply; sewerage, waste management and remediation activities (D); Construction (E); Wholesale and retail trade; repair of motor vehicles and motorcycles (F); Transportation and storage (G); Accommodation and food service activities (H); Information and communication (I); Financial and insurances activities (J); Professional, scientific and technical activities (K); Administrative and support service activities (L); Public administration and defiance; compulsory social security (M); Education (N); Human health and social work activities $(\mathbf{O})$; Arts, entertainment and recreation (P); Other service activities $(\mathbf{Q})$; Activities of households as employers; undifferentiated goods and services producing activities of households for own use (R); and Other scopes not previously included (S).

Countries such as Venezuela, Tunisia, Sweden South Africa, Slovenia, Poland, Mexico, Japan and Saudi Arabia only cover one area (Figure 5).

The United Kingdom is the location where the RULA method originated. However, it is not a place where it has been most applied, as only 11 studies have been performed there. The method originated with assessments carried out on workers in the industry [20]. Despite this, RULA has not been widely used in industry in the United Kingdom; it presents only three studies. "Human health and social work activities" stands out with five publications (Figure 5). 
Figure 6 shows the different countries according to the frequency of the published studies.

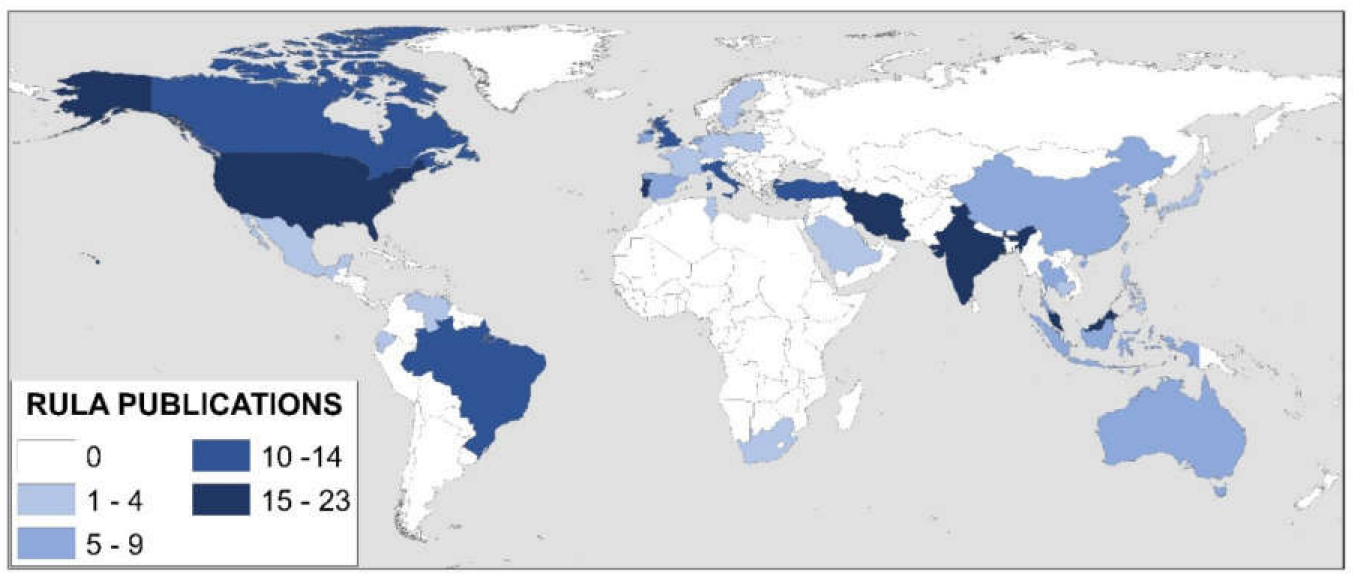

Figure 6. Map with frequencies.

\subsection{Classification by Years}

Figure 7 shows the period of time in which RULA has been used and in which areas of knowledge.

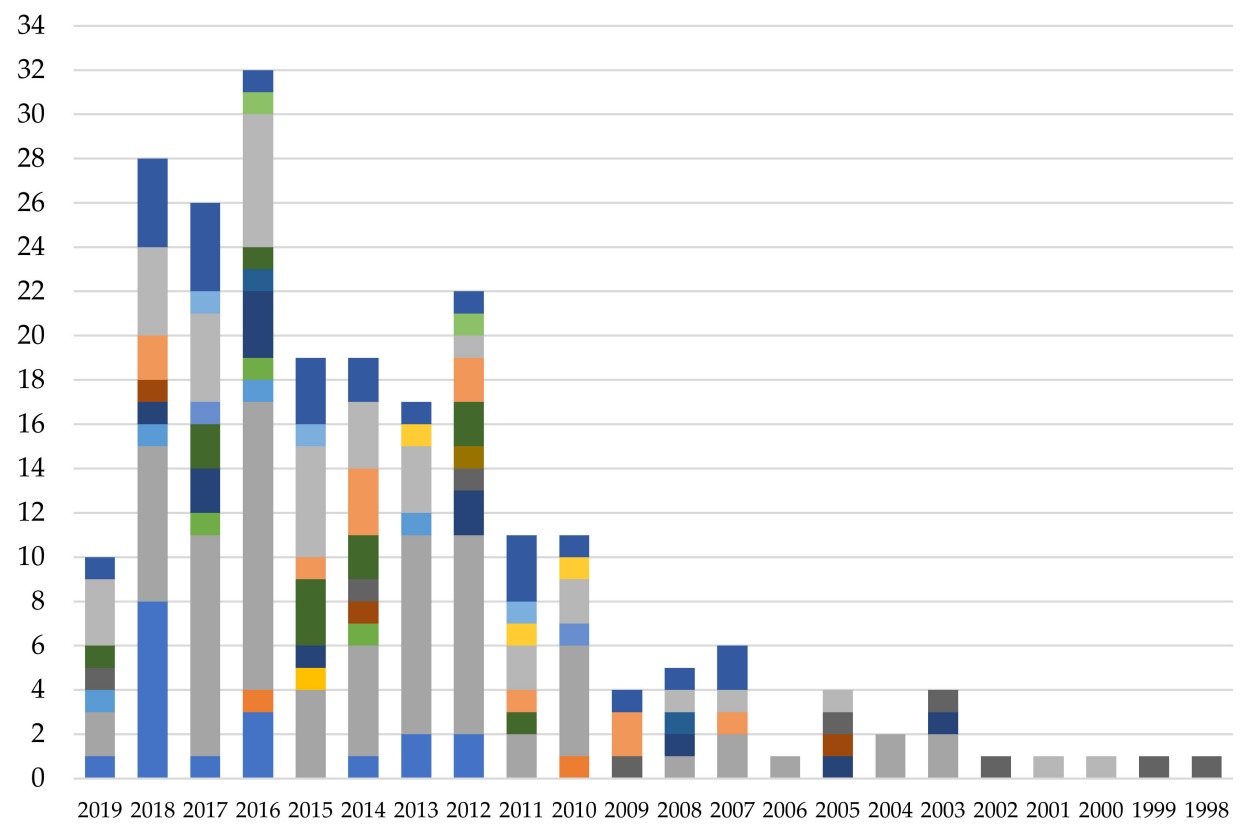

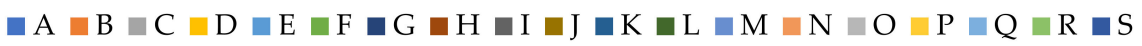

Figure 7. Number of studies classified by knowledge and year categories: Agriculture, forestry and fishing (A); Mining and quarrying (B); Manufacturing (C); Water supply; sewerage, waste management and remediation activities (D); Construction (E); Wholesale and retail trade; repair of motor vehicles and motorcycles (F); Transportation and storage (G); Accommodation and food service activities (H); Information and communication (I); Financial and insurances activities (J); Professional, scientific and technical activities (K); Administrative and support service activities (L); Public administration and defiance; compulsory social security (M); Education (N); Human health and social work activities $(\mathbf{O})$; Arts, entertainment and recreation (P); Other service activities (Q); Activities of households as employers; undifferentiated goods and services producing activities of households for own use (R); and Other scopes not previously included (S). 
The RULA method was created in 1993; however, according to the review carried out, it was not until 1998 that it was first applied.

From 1998 to 2019, the method has been applied every year. It should be noted that the year 2019 includes only the studies developed up until April.

The year 2016 stands out for the largest number of research studies (32). This is followed by the year 2018 with 28, 2017 with 26, 2012 with 22, 2014 and 2015 with 19 each, 2013 with 17 and 2010 and 2011 with 11 each. All other years have 10 or fewer studies.

Over the past 10 years, there has been an increase in such research. This may be due to the importance and awareness that occupational hazard prevention has received in recent times. In addition, it might be linked to the development of new technologies. These allow the method to be applied more quickly and efficiently (Figure 7).

It is noted (Figure 7) that over the past 10 years, the number of categories investigated has also increased compared to the previous 12 years. The year 2016 is characterised not only as having the largest number of publications, but also by the largest number of areas studied (11). "Manufacturing" stands out for representing 13 of the 32 research studies, followed by "Human health and social work activities" with 6. There are seven years with a single category (1998-2002, 2004 and 2006).

\subsection{Classification by Journal}

Table 22 presents all the journals available in this review, the number of articles published in each, knowledge categories (Web of Science), impact factor, rank and quartile. In total, 163 studies are differentiated. The rest of those that have been reviewed do not correspond to journal articles.

Table 22. Number of publications (N) by scientific journal, knowledge categories (Web of Science), impact factor, rank and quartile (2018).

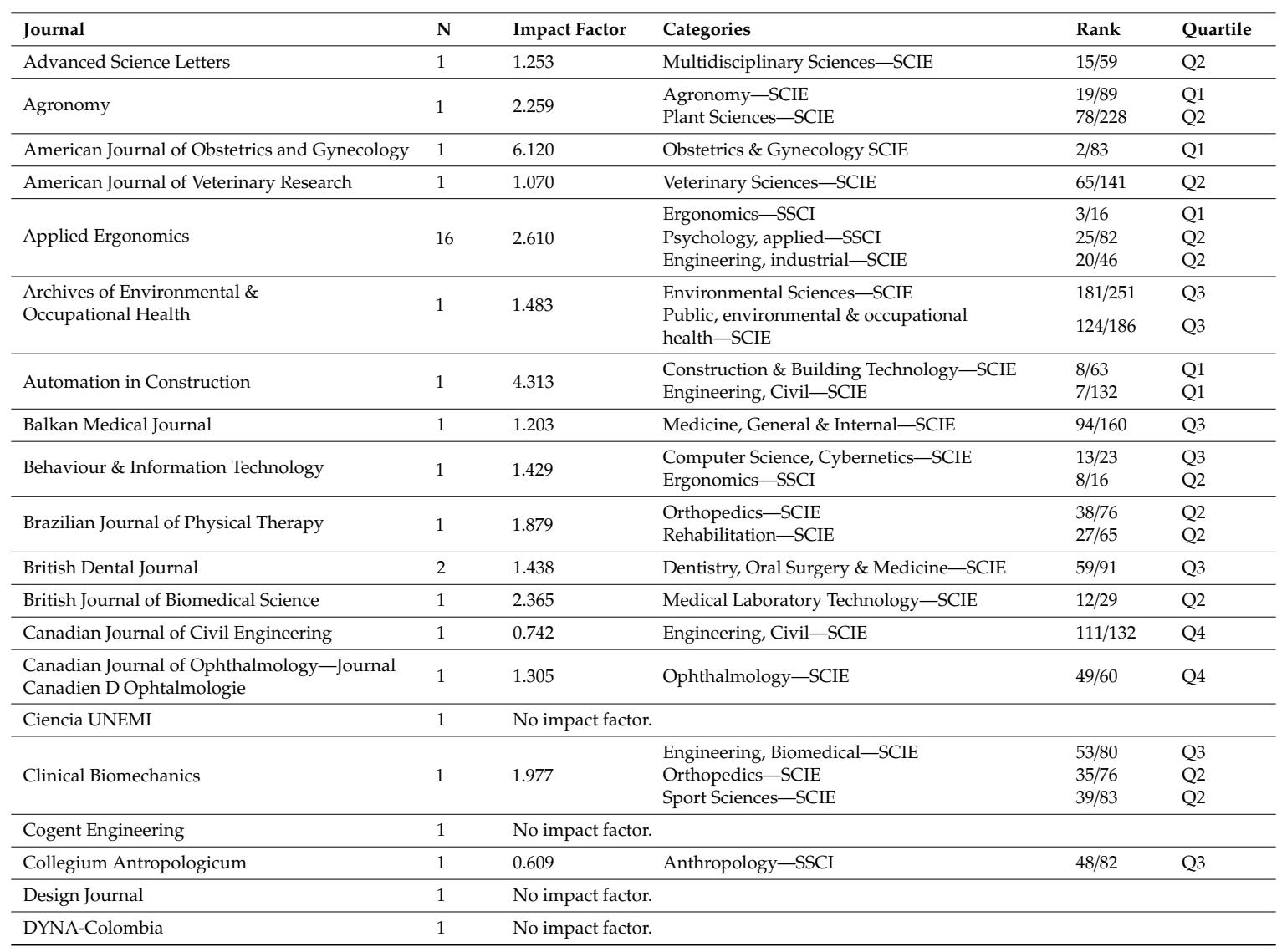


Table 22. Cont.

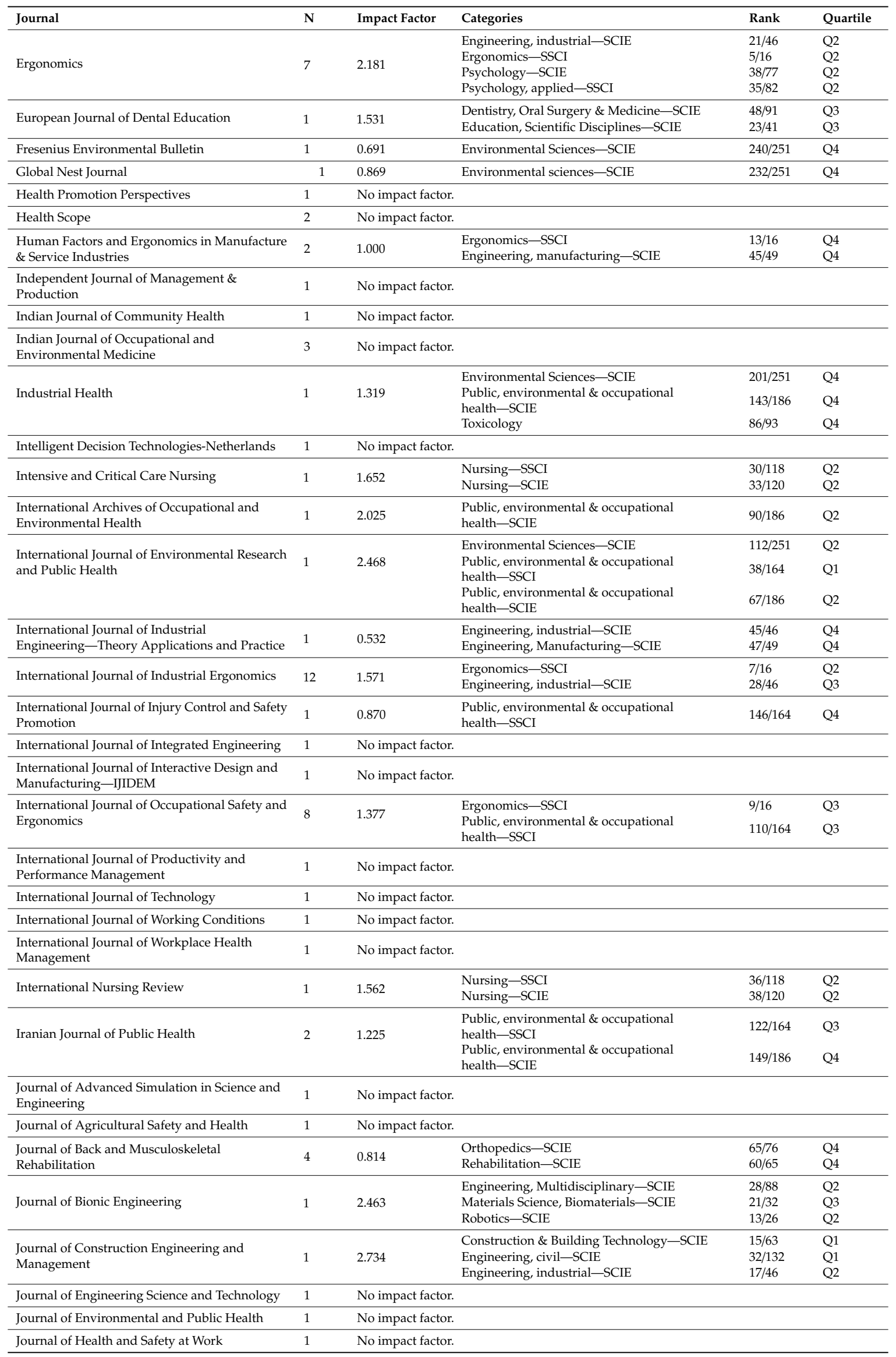


Table 22. Cont.

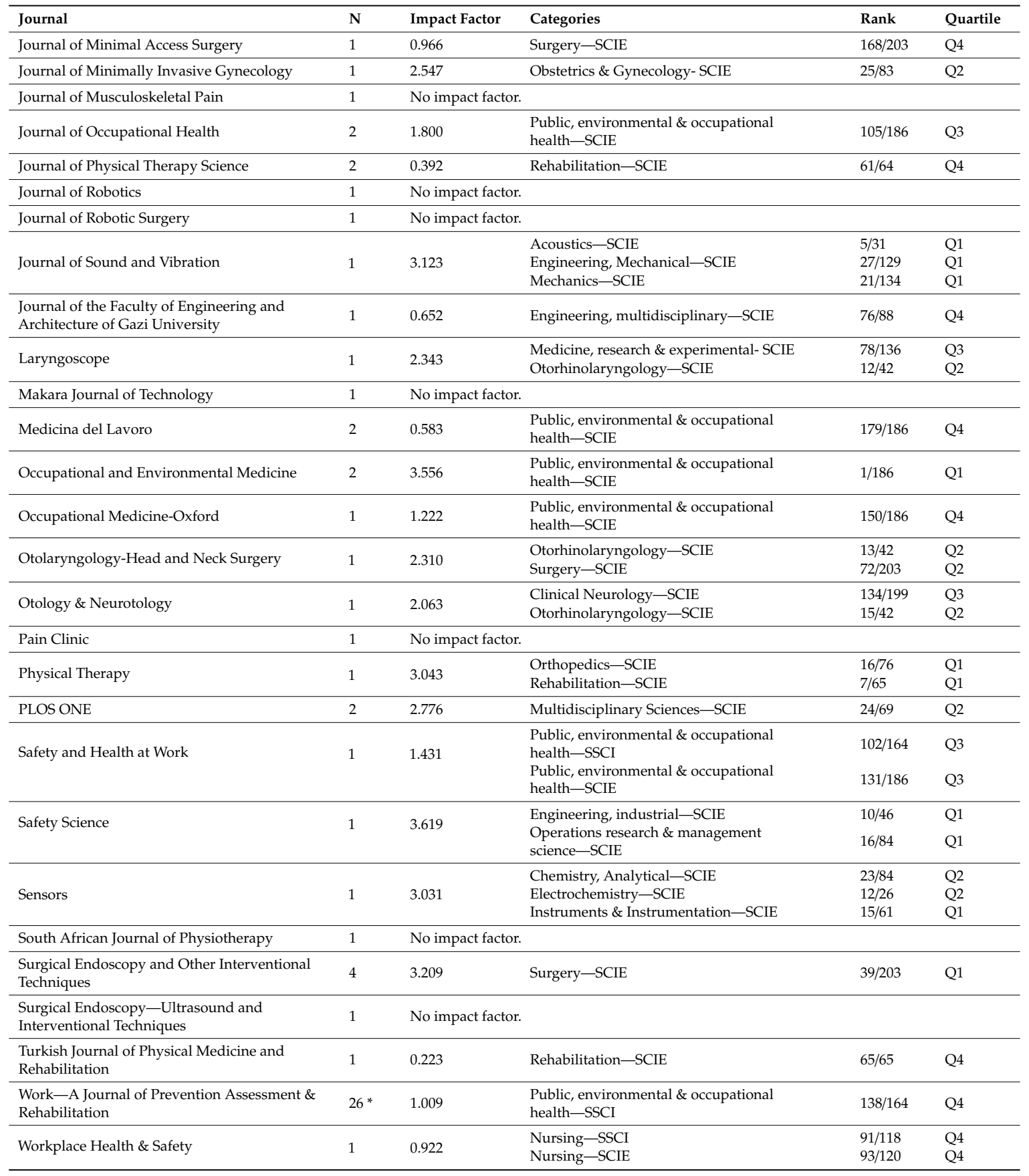

* Mode.

Of all the journals, there are four with a greater number of articles published: "Work-A Journal of Prevention Assessment \& Rehabilitation" with 26 studies, followed by "Applied Ergonomics" with 16, "International Journal of Industrial Ergonomics" with 12 and "International Journal of Occupational Safety and Ergonomics" with 8 (Table 22).

\subsection{Comparing Results with Other Methods}

Some bibliographic reviews similar to this one have already been carried out. They have focused on other indirect and semi-direct assessment methods. Some matches are presented in the results obtained.

The RULA method matches the OWAS method and the Standardized Nordic Questionnaire in the most common knowledge categories. The field of industry and health and social assistance are the 
most researched, with one or the other being highlighted depending on the method $[8,260]$. The REBA method has also been highlighted in industry, although the health-related field ranks fourth [261].

For countries with the highest number of publications, none of the methods coincided with RULA, since REBA excelled in India, OWAS in Finland and the Nordic Questionnaire in Iran. However, for REBA, the second country with the most studies was the USA $[8,260,261]$.

By date, the Nordic Questionnaire matches RULA. The year 2016 was when more studies were published for both [260].

Finally, with regards to journals, information is only available for the REBA method. The journal with the largest number of publications on this method is "Work-A Journal of Prevention Assessment \& Rehabilitation"; this is also the case for RULA [261].

It should be noted that this comparison is general since the date range selected in each of the studies is not the same.

\subsection{Sustainability and the RULA Method}

By integrating ISO 45001 with ISO 9001 and ISO 14001, organisations seek to implement quality management, occupational safety and health and the environment in a single system (Figure 8). The three systems, operating together, allow the organisation to optimise:

- The quality of the product or service

- Customer satisfaction

- The disposal of waste that has an impact on the environment

- The efficiency of the processes

- The health and safety of workers

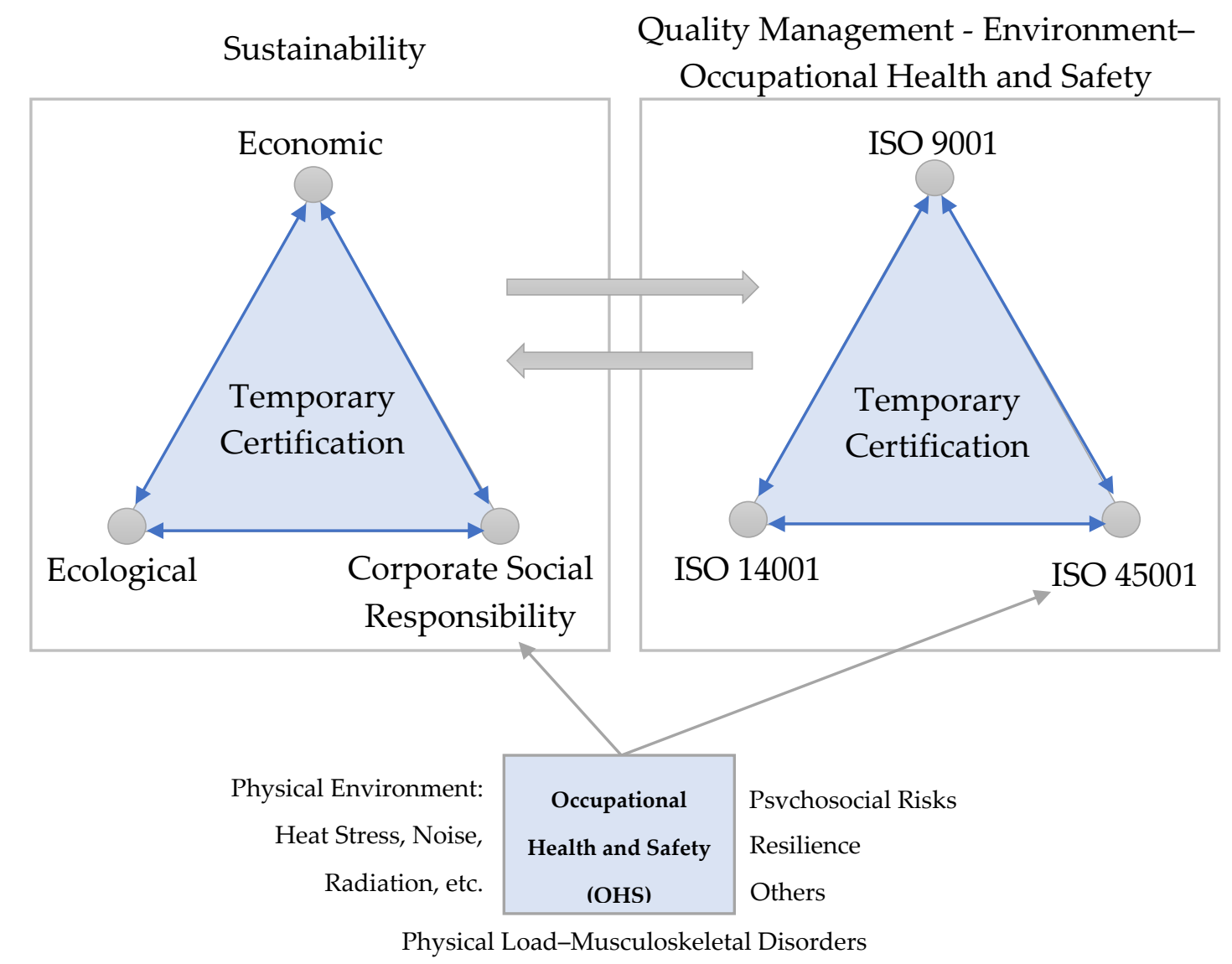

Figure 8. Parts of sustainability. 
Sustainability is a set of three fundamental parts: economic, social and environmental [262].

Sustainability, therefore, is not only focused on natural resources, but also plays a very important role in companies and contracted staff [263]. It fosters a relationship between healthy living and caring for nature [262]. For this reason, it is very important to also focus on the care of workers, carrying out assessments in order to obtain improvements in their health and safety [264].

The RULA method pursues this objective, as it focuses on the study of musculoskeletal disorders. Therefore, the use of this method contributes to the production of sustainable products.

\subsection{Limitations}

The country classification in this document has been based on the origin of the authors, as not all studies are clear about their location. The locations selected in each study have been those to which the greatest number of authors belong. In cases where it was not possible to follow this criterion, the location of the first author was selected.

\section{Conclusions}

The RULA method has been used in two main areas, "Manufacturing" and "Human health and social work activities". However, it has been found not to be a sector-specific method. It can be applied to workers in any field.

Its use has been increasing over the last 10 years, perhaps indicating it is an effective method which is being tested more and more. This is also coupled with a growing awareness of workers' health and safety. The year that stands out for the number of studies published is 2016 with a total of 32, followed by 2018 with a total of 28 .

Countries such as the USA and Iran excel at applying the method and encompassing numerous fields of knowledge. The journal with the most publications is "Work-A Journal of Prevention Assessment \& Rehabilitation", with a total of 26. This journal is followed by "Applied Ergonomics" with 16 published studies.

RULA is usually used in combination with other ergonomic methods or tools to provide better and more reliable results. In this way, it is possible to contemplate different risk factors and evaluate numerous body areas. In addition, technological advancement is also appreciated in all sectors, since in many studies the method is combined with the use of sensors, software, virtual reality, etc.

Author Contributions: Conceptualisation, M.G.-G., Á.-J.C.-F., J.P.-A., M.D.-P. and J.-A.C.-C.; methodology, M.G.-G., Á.-J.C.-F., J.P.-A., M.D.-P. and J.-A.C.-C.; software, M.G.-G., Á.-J.C.-F., J.P.-A., M.D.-P. and J.-A.C.-C.; validation, M.G.-G., Á.-J.C.-F., J.P.-A., M.D.-P. and J.-A.C.-C.; formal analysis, M.G.-G., Á.-J.C.-F., J.P.-A., M.D.-P. and J.-A.C.-C.; investigation, M.G.-G., Á.-J.C.-F., J.P.-A., M.D.-P. and J.-A.C.-C.; resources, M.G.-G., Á.-J.C.-F., J.P.-A., M.D.-P. and J.-A.C.-C.; data curation, M.G.-G., Á.-J.C.-F., J.P.-A., M.D.-P. and J.-A.C.-C.; writing-original draft preparation, M.G.-G., Á.-J.C.-F., J.P.-A., M.D.-P. and J.-A.C.-C.; writing-review and editing, M.G.-G., Á.-J.C.-F., J.P.-A., M.D.-P. and J.-A.C.-C.; visualisation, M.G.-G., Á.-J.C.-F., J.P.-A., M.D.-P. and J.-A.C.-C.; supervision, M.G.-G., Á.-J.C.-F., J.P.-A., M.D.-P. and J.-A.C.-C.; and project administration, M.G.-G., Á.-J.C.-F., J.P.-A., M.D.-P. and J.-A.C.-C. All authors have read and agreed to the published version of the manuscript.

Funding: This research received no external funding.

Acknowledgments: We acknowledge Laboratory-Observatory Andalusian Working Conditions in the Agricultural Sector (LASA; C.G. 401487) and the Research Own Plan of the University of Almería.

Conflicts of Interest: The authors declare no conflict of interest.

\section{Appendix A}

The following table shows a summary of the meanings of the abbreviations. 
Table A1. Abbreviations.

\begin{tabular}{|c|c|}
\hline Abbreviations & Meaning \\
\hline ALLA & Agricultural Lower Limb Assessment \\
\hline BCTQ & Boston Carpal Tunnel Syndrome Questionnaire \\
\hline CMDQ & Cornell Musculoskeletal Discomfort Questionnaire \\
\hline CTD & Cumulative Trauma Disorders \\
\hline DELMIA & Digital Enterprise Manufacturing Interactive Application \\
\hline EMG & Electromyograpgy \\
\hline FECYT & Spanish Foundation for Science and Technology \\
\hline HAL & Hand Activity Level \\
\hline IBV & Instituto de Biomecánica de Valencia (In Spanish) \\
\hline ICT & Information and Communications Technology \\
\hline iLMM & Industrial Lumbar Motion Monitor \\
\hline INSHT & Instituto Nacional de Seguridad e Higiene en el Trabajo (In Spanish) \\
\hline KIM & Key Indicator Method \\
\hline LBA & Lower Back Analysis \\
\hline LUBA & Loading on the Upper Body Assessment \\
\hline MAC & Manual Handling Assessment Charts \\
\hline ManTRA & Manual Task Risk Assessment \\
\hline MSD & Musculoskeletal Disorders \\
\hline NERPA & New Ergonomic Posture Assessment \\
\hline $\mathrm{NIOSH}$ & National Institute of Occupational Safety and Health \\
\hline NMSQ & Nordic Musculoskeletal Symptoms Questionnaire \\
\hline OBS & Office-based Surgery \\
\hline OCRA & Occupational Repetitive Action \\
\hline OSHA & Occupational Safety \& Health Administration \\
\hline OWAS & Ovako Working Analysis System \\
\hline PATH & Posture, Activity, Tools and Handling \\
\hline PEI & Posture Evaluation Index \\
\hline PLIBEL & $\begin{array}{l}\text { Method for the identification of musculoskeletal stress factors which may } \\
\text { have injurious effects }\end{array}$ \\
\hline PRRI & Posture and Repetition Risk Factor Index \\
\hline QEC & Quick Exposure Check \\
\hline QRating & Quick Rating \\
\hline REBA & Rapid Entire Body Assessment \\
\hline ROSA & Rapid Office Strain Assessment \\
\hline RULA & Rapid Upper Limb Assessment \\
\hline SI & Strain Index \\
\hline UEWD-R & Upper Extremity Work Demand \\
\hline VAS & Visual Analog Scale \\
\hline VDT & Visual Display Terminal \\
\hline VIRA & $\begin{array}{l}\text { Video film technique for Registration and Analysis of working postures and } \\
\text { movements }\end{array}$ \\
\hline WoS & Web of Science \\
\hline
\end{tabular}

\section{References}

1. European Agency for Safety and Health at Work (EU-OSHA). Trastornos Musculoesqueléticos. Available online: https://osha.europa.eu/es/themes/musculoskeletal-disorders (accessed on 21 January 2020).

2. European Agency for Safety and Health at Work (EU-OSHA). Preventing Work-Related Musculoskeletal Disorders. FACTS 4. Available online: https://osha.europa.eu/es/publications/factsheet-4-preventing-workrelated-musculoskeletal-disorders/view (accessed on 21 January 2020).

3. European Agency for Safety and Health at Work (EU-OSHA). Introduction to Work-Related Musculoskeletal Disorders. FACTS 71. Available online: https://osha.europa.eu/es/publications/factsheet-71-introductionwork-related-musculoskeletal-disorders/view (accessed on 21 January 2020). 
4. Asensio-Cuesta, S.; Diego-Mas, J.A.; Canos-Daros, L.; Andres-Romano, C. A genetic algorithm for the design of job rotation schedules considering ergonomic and competence criteria. Int. J. Adv. Manuf. Tech. 2012, 60, 1161-1174. [CrossRef]

5. Ilonca, I.; Stanciu, A.; Rosulescu, E.; Zavaleanu, M.; Cosma, G. Ergonomics and exercises program as practical solutions for the prevention of musculoskeletal disorders in clinical dentistry. In Proceedings of the 3rd International Multidisciplinary Scientific Conference on Social Sciences and Arts, SGEM 2016, Albena, Bulgaria, 24-30 August 2016; pp. 445-452.

6. Nunes, I.L. FAST ERGO_X-A tool for ergonomic auditing and work-related musculoskeletal disorders prevention. Work 2009, 34, 133-148. [CrossRef] [PubMed]

7. Batubara, H.; Dharmastiti, R. Redesign of liquid aluminum pouring tool based on participatory ergonomics to improve productivity, workload, and musculoskeletal disorders. Int. J. Technol. 2017, 8, 352-361. [CrossRef]

8. Gomez-Galan, M.; Perez-Alonso, J.; Callejon-Ferre, A.J.; Lopez-Martinez, J. Musculoskeletal disorders: OWAS review. Ind. Health 2017, 55, 314-337. [CrossRef]

9. Alvarez-Zarate, J.M.; Marin-Zurdo, J.J.; Sistema HADA Move-Human Sensors. Sistema Portátil para Captura y Análisis Tridimensional del Movimiento Humano en Puestos de Trabajo Basado en Sensores Inerciales de Movimiento y Simulación 3D con Modelos Biomecánicos. Available online: http://www.seguridad-laboral. es/prevencion/ergonomia/sistema-hada-move-human-sensors (accessed on 22 January 2020).

10. Kuorinka, I.; Jonsson, B.; Kilbom, A.; Vinterberg, H.; Biering-Sorensen, F.; Andersson, G.; Jorgensesn, K. Standardised Nordic questionnaires for the analysis of musculoskeletal symptoms. Appl. Ergon. 1987, 18, 233-237. [CrossRef]

11. Lifshitz, Y.; Amstrong, T. A design checklist for control and prediction of cumulative trauma disorders in hand intensive manual jobs. In Proceedings of the 30th Annual Meeting of Human Factors Society, Dayton, OH, USA, 29 September-3 October 1986; pp. 837-841. [CrossRef]

12. David, G.; Woods, V.; Li, G.; Buckle, P. The development of the Quick Exposure Check (QEC) for assessing exposure to risk factors for work-related musculoskeletal disorders. Appl. Ergon. 2008, 39, 57-69. [CrossRef] [PubMed]

13. Keyserling, W.M.; Stetson, D.S.; Silverstein, B.A.; Brouwer, M.L. A checklist for evaluating ergonomic risk factors associated with upper extremity cumulative trauma disorders. Ergonomics 1993, 36, 807-831. [CrossRef] [PubMed]

14. Jürgens, W.W.; Mohr, D.; Pangert, R.; Pernack, E.; Schultz, K.; Steinberg, U. Handlungsanleitung zur Beurteilung der Arbeitsbedingungen beim Heben und Tragen von Lasten; LASI Veröffentlichung: Wiesbaden, Germany, 2001; Volume 9.

15. Instituto Nacional de Seguridad y Salud en el Trabajo (INSST). Guía Técnica para la Evaluación y Prevención de los Riesgos Relativos a la Manipulación Manual de Cargas. Guías Técnicas; INSST: Madrid, Spain, 1998.

16. Monnington, S.; Quarrie, C.; Pinder, A.; Morris, L. Development of Manual Handling Assessment Charts (MAC) for health and safety inspectors. In Contemporary Ergonomics; Taylor \& Francis: London, UK, 2003.

17. Liberty-Mutual. Manual Materials Handling Tables. Available online: https://ibertymmhtables. libertymutual.com/CM_LMTablesWeb/taskSelection.do?action=initTaskSelection (accessed on 22 January 2019).

18. National Institute for Occupational Safety and Health (NIOSH). Work Practices Guide for Manual Lifting; NIOSH Technical Report; NIOSH: Cincinnaty, OH, USA, 1981; pp. 81-122.

19. Snook, S.H.; Ciriello, V.M. The design of manual handling tasks: Revised tables of maximum acceptable weights and forces. Ergonomics 1991, 34, 1197-1213. [CrossRef]

20. McAtamney, L.; Corlett, E.N. RULA-A survey method for the investigation of work-related upper limb disorders. App. Ergon. 1993, 24, 91-99. [CrossRef]

21. Kemmlert, K. A method assigned for the identification of ergonomic hazards-PLIBEL. Appl. Ergon. 1995, 26, 199-211. [CrossRef]

22. Moore, J.S.; Garg, A. The Strain Index: A proposed method to analyze jobs for risk of distal upper extremity disorders. Am. Ind. Hyg. Assoc. J. 1995, 56, 443-458. [CrossRef] [PubMed]

23. Colombini, D. An observational method for classifying exposure to repetitive movements of the upper limbs. Ergonomics 1998, 41, 1261-1289. [CrossRef] [PubMed]

24. García, C.; Chirivela, C.; Page del Pozo, A.; Moraga, R.; Jorquera, J. Método Ergo IBV. Evaluación de Riesgos Laborales Asociados a la Carga Física; Instituto de Biomecánica de Valencia (IBV): Valencia, Spain, 1997. 
25. James, C.P.A.; Harburn, K.L.; Kramer, J.F. Cumulative trauma disorders in the upper extremities: Reliability of the Postural and Repetitive Risk-Factors Index. Arch. Phys. Med. Rehab. 1997, 78, 860-866. [CrossRef]

26. Hignett, S.; McAtamney, L. Rapid Entire Body Assessment (REBA). Appl. Ergon. 2000, 31, 201-205. [CrossRef]

27. Buchholz, B.; Paquet, V.; Punnett, L.; Lee, D.; Moir, S. PATH: A work sampling-based approach to ergonomic job analysis for construction and other non-repetitive work. Appl. Ergon. 1996, 27, 177-187. [CrossRef]

28. Karhu, O.; Kansi, P.; Kuorinka, I. Correcting working postures in industry: A practical method for analysis. Appl. Ergon. 1977, 8, 199-201. [CrossRef]

29. Kilbom, A.; Persson, J.; Jonsson, B. Risk factors for work-related disorders of the neck and shoulder-With special emphasis on working postures and movements. In The Ergonomics of Working Postures; Corlett, E.N., Wilson, J., Manenica, I., Eds.; Taylor \& Francis: London, UK, 1986; pp. 44-53.

30. Corlett, E.; Madeley, S.; Manenica, I. Posture targeting: A technique for recording working postures. Ergonomics 1979, 22, 357-633. [CrossRef]

31. Instituto de Ergonomía (INERMAP). Ergomet 3.0. Available online: http://www.inermap.com/software/ ergomet.html (accessed on 22 January 2020).

32. Takala, E.P.; Pehkonen, I.; Forsman, M.; Hansson, G.A.; Mthiassen, S.E.; Neumann, W.P.; Sjogaard, G.; Veiersted, K.B.; Westgaard, R.H.; Winkel, J. Systematic evaluation of observational methods assessing biomechanical exposures at work. Scand. J. Work. Environ. Health. 2010, 36, 3-24. [CrossRef]

33. Eurostat. NACE Rev. 2. Structure and Explanatory Notes. Available online: https: //ec.europa.eu/eurostat/documents/1965800/1978839/NACE_rev2_explanatory_notes_EN.pdf/b09f2cb45dac-4118-9164-bcc39b791ef5 (accessed on 4 October 2019).

34. Cremasco, M.M.; Giustetto, A.; Caffaro, F.; Colantoni, A.; Cavallo, E.; Grigolato, S. Risk assessment for musculoskeletal disorders in forestry: A comparison between RULA and REBA in the manual feeding of a wood-chipper. Int. J. Environ. Res. Public Health 2019, 16, 793. [CrossRef]

35. Pramchoo, W.; Geater, A.F.; Harris-Adamson, C.; Tangtrakulwanich, B. Ergonomic rubber tapping knife relieves symptoms of carpal tunnel syndrome among rubber tappers. Int. J. Ind. Ergonom. 2018, 68, 65-72. [CrossRef]

36. Kim, E.; Freivalds, A.; Takeda, F.; Li, C. Ergonomic evaluation of current advancements in blueberry harvesting. Agronomy 2018, 8, 266. [CrossRef]

37. Pal, A.; Dhara, P.C. Work related musculoskeletal disorders and postural stress of the women cultivators engaged in uprooting job of rice cultivation. Ind. J. Occup. Environ. Med. 2018, 22, 163-169. [CrossRef]

38. Thetkathuek, A.; Meepradit, P.; Sangiamsak, T. A cross-sectional study of musculoskeletal symptoms and risk factors in Cambodian fruit farm workers in Eastern Region, Thailand. Saf. Health Work 2018, 9, 192-202. [CrossRef]

39. Jain, R.; Meena, M.L.; Dangayach, G.S.; Bhardwaj, A.K. Association of risk factors with musculoskeletal disorders in manual-working farmers. Arch. Environ. Occup. Health 2018, 73, 19-28. [CrossRef] [PubMed]

40. Pardo-Ferreira, M.C.; Zambrana-Ruiz, A.; Carrillo-Castrillo, J.A.; Rubio-Romero, J.C. Ergonomic risk management of pruning with chainsaw in the olive sector. In Proceedings of the 6th International Symposium on Occupational Safety and Hygiene (SHO), Guimaraes, Portugal, 26-27 March 2018; Arezes, P.M., Baptista, J.S., Barroso, M.P., Carneiro, P., Cordeiro, P., Costa, N., Melo, R.B., Miguel, A.S., Perestrelo, G., Eds.; pp. 517-522.

41. Jain, R.; Meena, M.L.; Dangayach, G.S.; Bhardwaj, A.K. Risk factors for musculoskeletal disorders in manual harvesting farmers of Rajasthan. Ind. Health 2018, 56, 241-248. [CrossRef] [PubMed]

42. Kong, Y.K.; Lee, S.Y.; Lee, K.S.; Kim, D.M. Comparisons of ergonomic evaluation tools (ALLA, RULA, REBA and OWAS) for farm work. Int. J. Occup. Saf. Ergo. 2018, 24, 218-223. [CrossRef]

43. Unver-Okan, S.; Acar, H.H.; Kaya, A. Determination of work postures with different ergonomic risk assessment methods in forest nurseries. Fresen. Environ. Bull. 2017, 26, 7362-7371.

44. Putri, N.T.; Susanti, L.; Tito, A.; Sutanto, A. Redesign of thresher machine for farmers using Rapid Upper Limb Assessment (RULA) method. In Proceedings of the IEEE International Conference on Industrial Engineering and Engineering Management (IEEM), Bali, Indonesia, 4-7 December 2016; pp. 1304-1309.

45. Vazquez-Cabrera, F.J. Ergonomic evaluation, with the RULA method, of greenhouse task of trellising crops. Work 2016, 54, 517-531. [CrossRef] 
46. Mohd Nasir, N.S.; Mohd Tamrin, S.B.; Subramanian, K.; Shukoor, N.S.; Zolkifli, N.; Ng, G.S.; Muhamad Akir, N.F.; Ananta, G.P. Association of workplace stressors with salivary alpha-amylase activity levels among fresh fruit bunch cutters in Selangor. Iran. J. Public Health 2016, 45, 68-76.

47. Deros, B.M.; Khamis, N.K.; Mohamad, D.; Kabilmiharbi, N.; Daruis, D.D.I. Investigation of oil palm harvesters' postures using RULA analysis. In Proceedings of the IEEE International Conference on Biomedical Engineering and Sciences, Miri, Malaysia, 8-10 December 2014; pp. 287-290.

48. Mokhtar, M.M.; Deros, B.M.; Sukadarin, E.H. Evaluation of musculoskeletal disorders prevalence during oil palm fresh fruit bunches harvesting using RULA. In Proceedings of the 2nd International Conference on Ergonomics (ICE 2013), Kuala Lumpur, Malaysia, 2-4 September 2013; Yusuff, R.M., Ahmad, S.A., Daruis, D.D.I., Deros, B.M., Dawal, S.Z.M., Eds.; pp. 110-150.

49. Swangnetr, M.; Namkorn, P.; Phimphasak, C.; Saenlee, K.; Kaber, D.; Buranruk, O.; Puntumetakul, R. Ergonomic analysis of rice field plowing. In Advanced in Physical Ergonomics and Safety; Ahram, T.Z., Karwowski, W., Eds.; CRC Press: Boca Raton, FL, USA, 2013; pp. 565-574.

50. Di Gironimo, G.; Lanzotti, A.; Melemez, K.; Renno, F. Atop-down approach for virtual redesign and ergonomic optimization of an agricultural tractor's driver cab. In Proceedings of the 11th ASME Biennial Conference on Engineering Systems Design and Analysis, (ESDA 2012), Nantes, France, 2-4 July 2012; pp. 801-811.

51. Meksawi, S.; Tangtrakulwanich, B.; Chongsuvivatwong, V. Musculoskeletal problems and ergonomic risk assessment in rubber tappers: A community-based study in southern Thailand. Int. J. Ind. Ergonom. 2012, 42, 129-135. [CrossRef]

52. Mukhopadhyay, P.; Srivastava, S. Evaluating ergonomic risk factors in non-regulated stone carving units of Jaipur. Work 2010, 35, 87-99. [CrossRef] [PubMed]

53. Norhidayah, M.S.; Mohamed, N.M.Z.N.; Mansor, M.A.; Ismail, A.R. RULA: Postural loading assessment tools for Malaysia mining industry. J. Eng. Sci. Technol. 2016, 11, 1-8.

54. Azizi, A.; Yazdi, P.G.; Hashemipour, M. Interactive design of storage unit utilizing virtual reality and ergonomic framework for production optimization in manufacturing industry. Int. J. Interact. Des. Manuf. IJIDEM 2019, 13, 373-381. [CrossRef]

55. Fazi, H.B.M.; Mohamed, N.M.Z.B.N.; Bin Basri, A.Q. Risks assessment at automotive manufacturing company and ergonomic working condition. In Proceedings of the 1st International Postgraduate Conference on Mechanical Engineering (IPCME), Pahang, Malaysia, 31 October 2018.

56. Sain, M.K.; Meena, M.L. Exploring the musculoskeletal problems and associated risk-factors among brick kiln workers. Int. J. Workpl. Health Manag. 2018, 11, 395-410. [CrossRef]

57. Boulila, A.; Ayadi, M.; Mrabet, K. Ergonomics study and analysis of workstations in Tunisian mechanical manufacturing. Hum. Factor. Ergon. Man. 2018, 28, 166-185. [CrossRef]

58. Gregory, D.E.; Romero, S.E. Can the use of an alternatively designed tamper alter spine posture and risk of upper limb injury while tamping espresso? Int. J. Ind. Ergonom. 2018, 65, 103-109. [CrossRef]

59. Daneshmandi, H.; Kee, D.; Kamalinia, M.; Oliaei, M.; Mohammadi, H. An ergonomic intervention to relieve musculoskeletal symptoms of assembly line workers at an electronic parts manufacturer in Iran. Work 2018, 61, 515-521. [CrossRef]

60. Yahya, N.M.; Zahid, M.N.O. Work-related musculoskeletal disorders (WMDs) risk assessment at core assembly production of electronic components manufacturing company. In Proceedings of the 4th Asia Pacific Conference on Manufacturing Systems/3rd International Manufacturing Engineering Conference (APCOMS-iMEC), Yogyakarta, Indonesia, 7-8 December 2017.

61. Yazdanirad, S.; Khoshakhlagh, A.H.; Habibi, E.; Zare, A.; Zeinodini, M.; Dehghani, F. Comparing the effectiveness of three ergonomic risk assessment methods-RULA, LUBA and NERMA-To predict the upper extremity musculoskeletal disorders. Ind. J. Occup. Environ. Med. 2018, 22, 17-21. [CrossRef]

62. Tang, G.; Webb, P. The design and evaluation of an ergonomic contactless gesture control system for industrial robots. J. Robotic 2018, 9791286. [CrossRef]

63. Mat, S.; Abdullah, M.A.; Dullah, A.R.; Shamsudin, S.A.; Hussin, M.F. Car seat design using RULA analysis. In Proceedings of the 4th Mechanical Engineering Research Day (MERD), Melaka, Malaysia, 30 March 2017; BonAbdoollah, M.F., Tuan, T.B., Salim, M.A., Akop, M.Z., Ismail, R., Musa, H., Eds.; pp. 130-131. 
64. Ziaei, M.; Ziaei, H.; Hosseini, S.Y.; Gharagozlou, F.; Keikshamoghaddam, A.A.; Laybidi, M.I.; Moradinazar, M. Assessment and virtual redesign of a manual handling Workstation by computer-aided three-domensional interactive application. Int. J. Occup. Saf. Ergo. 2017, 23, 169-174. [CrossRef]

65. Fazi, H.M.; Mohamed, N.M.Z.N.; Ab Rashid, M.F.F.; Rose, A.N.M. Ergonomics study for workers at food production industry. In Proceedings of the 2nd International Conference on Automotive Innovation and Green Vehicle (AiGEV), Cyberjaya, Malaysia, 2-3 August 2016; Ghani, S.A.C., Hamzah, W.A.W., Alias, A., Eds.;

66. Alabdulkarim, S.; Nussbaum, M.A.; Rashedi, E.; Kim, S.; Agnew, M.; Gardner, R. Impact of task design on task performance and injury risk: Case study of a simulated drilling task. Ergonomics 2017, 60, 851-866. [CrossRef] [PubMed]

67. Vosniakos, G.C.; Deville, J.; Matsas, E. On inmersive virtual environments for assessing human-driven assembly of large mechanical parts. In Proceedings of the 27th International Conference on Flexible Automation and Intelligent Manufacturing (FAIM), Modena, Italy, 27-30 June 2017; Pellicciari, M., Peruzzini, M., Eds.; pp. 1263-1270.

68. Lockett, H.L.; Arvanitopoulos-Darginis, K. An Automated Maintainability Prediction Tool Integrated with Computer Aided Design. In Proceedings of the 27th CIRP Design Conference, Cranfield, UK, 10-12 May 2017; Shehab, E., Tomiyama, T., Lockett, H., Salonitis, K., Roy, R., Tiwari, A., Eds.; pp. 440-445.

69. Binoosh, S.A.; Mohan, G.M.; Ashok, P.; Sekaran, K.D. Virtual postural assessment of an assembly work in a small scale submersible pump manufacturing industry. Work 2017, 58, 567-578. [CrossRef] [PubMed]

70. Carlos, S.R.; Cesar, R.M.; Rosa, G.P.; Edwin, P. Evaluation factors musculoskeletal risk area shoe fitting. Ciencia UNEMI 2017, 10, 69-80.

71. Labbafinejad, Y.; Danesh, H.; Imanizade, Z. Assessment of upper limb musculoskeletal pain and posture in workers of packaging units of pharmaceutical industries. Work 2017, 56, 337-344. [CrossRef]

72. Nahavandi, D.; Hossny, M. Skeleton-free RULA ergonomic assessment using Kinect sensors. Intel. Decis. Technol. 2017, 11, 275-284. [CrossRef]

73. Monteiro, L.; Santos, J.; Santos, V.; Franca, V.; Alsina, O. Analysis of overload in the musculoskeletal system of women developing repetitive tasks in fluid filling process in chemical industry. In Proceedings of the 12th International Symposium on Occupational Safety and Hygiene of Portuguese-Society-of-Occupational-Safety-and-Hygiene (SHO), Guimaraes, Portugal, 23-24 March 2016; Arezes, P.M., Baptista, J.S., Barroso, M.P., Carneiro, P., Cordeiro, P., Costa, N., Melo, R.B., Miguel, A.S., Perestrelo, G., Eds.; pp. 29-33.

74. Kushwaha, D.K.; Kane, P.V. Ergonomic assessment and workstation design of shipping crane cabin in steel industry. Int. J. Ind. Ergonom. 2016, 52, 29-39. [CrossRef]

75. Silva, L.; Carneiro, P.; Braga, A.C. Work-related musculoskeletal disorders of the upper limbs in an auto components company. In Proceedings of the 12th International Symposium on Occupational Safety and Hygiene of Portuguese-Society-of-Occupational-Safety-and-Hygiene (SHO), Guimaraes, Portual, $23-24$ March 2016; Arezes, P.M., Baptista, J.S., Barroso, M.P., Carneiro, P., Cordeiro, P., Costa, N., Melo, R.B., Miguel, A.S., Perestrelo, G., Eds.; pp. 463-468.

76. Kumar, P.; Chakrabarti, D.; Patel, T.; Chowdhuri, A. Work-related pains among the workers associated with pineapple peeling in small fruit processing units of North East India. Int. J. Ind. Ergonom. 2016, 53, 124-129. [CrossRef]

77. Thetkathuek, A.; Meepradit, P.; Jaidee, W. Factors affecting the musculoskeletal disorders of workers in the frozen food manufacturing factories in Thailand. Int. J. Occup. Saf. Ergo. 2016, 22, 49-56. [CrossRef]

78. Veisi, H.; Choobineh, A.R.; Ghaem, H. Musculoskeletal problems in Iranian hand-woven shoe-sole making operation and developing guidelines for workstation design. Int. J. Occup. Environ. Med. 2016, 7, 87-97. [CrossRef]

79. Labbafinejad, Y.; Imanizade, Z.; Danesh, H. Ergonomic risk factors and their association with lower back and neck pain among pharmaceutical employees in Iran. Workpl. Health Saf. 2016, 64, 586-595. [CrossRef]

80. Dianat, I.; Karimi, M.A. Musculoskeletal symptoms among handicraft workers engaged in hand sewing tasks. J. Occup. Health 2016, 58, 644-652. [CrossRef] [PubMed]

81. Ravichandran, S.P.; Shah, P.B.; Lakshminarayanan, K.; Ravichandran, A.P. Musculoskeletal problems among workers in a garment industry, at Tirupur, Tamil Nadu. Ind. J. Community Health 2016, 28, 269-274. 
82. Sutari, W.; Andias, R.; Doyoyekti, Y.N.; Dwiastuti, M.; Mufidah, I. Musculoskeletal disorder: An Indonesian "Batik Cap" industry case study. Adv. Sci. Lett. 2016, 22, 1824-1826. [CrossRef]

83. Van, L.; Chaiear, N.; Sumananont, C.; Kannarath, C. Prevalence of musculoskeletal symptoms among garment workers in Jandal province, Cambodia. J. Occup. Health 2016, 58, 107-117. [CrossRef]

84. Coelho, C.; Oliveira, P.; Maia, E.; Maia, J.; Dias-Teixera, M. The importance of ergonomics analysis in prevention of MSDs: A pilot study. In Proceedings of the International Conference on Safety Management and Human Factors, Orlando, FL, USA, 27-31 July 2016; Arezes, P., Ed.; pp. 139-151.

85. Zhao, L.Z.; Zhang, Y.H.; Wu, X.H.; Yan, J.H. Virtual assembly simulation and ergonomics analysis for the industrial manipulator based on DELMIA. In Proceedings of the 6th International Asia Conference on Industrial Engineering and Management Innovation (IEMI), Tianjin, China, 25-26 July 2015; Qi, E., Ed.; pp. 527-538.

86. Almeida, M.D.; Laranieira, P.; Rebelo, M. Risk assessment in maintenance of a rehm reflow oven V8. In Proceedings of the International Symposium on Occupational Safety and Hygiene (SHO), Guimaraes, Portugal, 12-13 February 2015; Arezes, P., Baptista, J.S., Barroso, M.P., Carneiro, P., Cordeiro, P., Costa, N., Melo, R., Miguel, A.S., Perestrelo, G., Eds.; pp. 6-8.

87. Dianat, I.; Kord, M.; Yahyazade, P.; Karimi, M.A.; Stedmon, A.W. Association of individual and work-related risk factors with musculoskeletal symptoms among Iranian sewing machine operators. Appl. Ergon. 2015, 51, 180-188. [CrossRef]

88. Sutari, W.; Yekti, Y.N.D.; Astuti, M.D.; Sari, Y.M. Analysis of working posture on muscular skeleton disorders of operator in stamp scraping in 'batik cap' industry. In Proceedings of the International Conference on Industrial Engineering and Service Science (IESS), Yogyakarta, Indonesia, 1-2 September 2015; Puiawan, N., Ciptomulyono, U., Baihaqi, I., Santosa, B., Eds.; pp. 133-138.

89. Rivero, L.C.; Rodriguez, R.G.; Perez, M.D.; Mar, C.; Juarez, Z. Fuzzy logic and RULA method for assessing the risk of working. In Proceedings of the 6th International Conference on Applied Human Factors and Ergonomics (AHFE), Las Vegas, NV, USA, 26-30 July 2015; Ahram, T., Karwowski, W., Schmorrow, D., Eds.; pp. 4816-4822.

90. Halim, I.; Mahmood, A.R.; Hasan, H.; Sihombing, H.; Saptari, A.; Abu Bakar, B.; Ahmad, S. Ergonomic design of CNC milling machine for safe working posture. In Proceedings of the 4th International Conference on Mechanical and Manufacturing Engineering (ICME 2013), Bangi Putrajaya, Malaysia, 17-18 December 2013; Ismail, A.E., Nor, N.H.M., Ali, M.F.M., Ahmad, R., Masood, I., Tobi, A.L.M., Ghafir, M.F.A., Muhammad, M., Wahab, M.S., Zain, B.A.M., Eds.; pp. 60-64.

91. Dianat, I.; Salimi, A. Working conditions of Iranian hand-sewn shoe workers and associations with musculoskeletal symptoms. Ergonomics 2014, 57, 602-611. [CrossRef]

92. Mendes, A.C.; Moreira, J.; Maia, R.; Goncalves, M.A. Ergonomic work analysis of swing arm cutting machine by RULA method. In Proceedings of the 10th Annual Congress of the Portuguese-Society-of-Occupational-Safety-and-Hygiene on Occupational Safety and Hygiene (SPOSHO), Guimaraes, Portugal, 13-14 February 2014; Arezes, P.M., Baptista, J.S., Barroso, M.P., Carneiro, P., Cordeiro, P., Costa, N., Melo, R.B., Miguel, A.S., Perestrelo, G., Eds.; pp. 743-748.

93. Bolzan, G.N.; Freitas, G.S.; Franz, L.A.S. A study regarding the ergonomic conditions in an area of winding transformers. In Proceedings of the 10th Annual Congress of the Portuguese-Society-of-Occupational-Safety-and-Hygiene on Occupational Safety and Hygiene (SPOSHO), Guimaraes, Portugal, 13-14 February 2014; Arezes, P.M., Baptista, J.S., Barroso, M.P., Carneiro, P., Cordeiro, P., Costa, N., Melo, R.B., Miguel, A.S., Perestrelo, G., Eds.; pp. 247-252.

94. Coelho, C.; Oliveira, P.; Maia, E.; Rangel, R.; Dias-Teixeira, M. The importance of ergonomics analysis in prevention of MSDs: Exploratory study in Swedwood-Portugal. In Proceedings of the 10th Annual Congress of the Portuguese-Society-of-Occupational-Safety-and-Hygiene on Occupational Safety and Hygiene (SPOSHO), Guimaraes, Portugal, 13-14 February 2014; Arezes, P.M., Baptista, J.S., Barroso, M.P., Carneiro, P., Cordeiro, P., Costa, N., Melo, R.B., Miguel, A.S., Perestrelo, G., Eds.; pp. 725-729.

95. Garcia-Garcia, M.; Sanchez-Lite, A.; Camacho, A.M.; Domingo, R. Analysis of postural assessment methods and virtual simulation tools into manufacturing engineering. DYNA 2013, 80, 5-15.

96. Vathna, M.; Abdullah, N.S.; Dawal, S.Z.M.; Aoyama, H.; Sothea, K. Investigation on musculoskeletal symptoms and ergonomic risk factors at metal stamping industry. In Proceedings of the 2nd International Conference on Ergonomics (ICE 2013), Kuala Lumpur, Malaysia, 2-4 September 2013; Yusuff, R.M., Ahmad, S.A., Daruis, D.D.I., Deros, B.M., Dawal, S.Z.M., Eds.; p. 293. 
97. Berberoglu, U.; Tokuc, B. Work-related musculoskeletal disorders at two textile factories in Edirne, Turkey. Balk. Med. J. 2013, 30, 23-27. [CrossRef]

98. Yusof, N.; Yusof, R.; Basri, F.M.F.A.; Soin, N. Ergonomic evaluation of postural assessment among "canting" batik workers. In Proceedings of the 2nd International Conference on Ergonomics (ICE 2013), Kuala Lumpur, Malaysia, 2-4 September 2013; Yusuff, R.M., Ahmad, S.A., Daruis, D.D.I., Deros, B.M., Dawal, S.Z.M., Eds.; p. 226.

99. Jaturanonda, C.; Nanthavanij, S.; Das, S.K. Heuristic procedure for the assembly line balancing problem with postural load smoothness. Int. J. Occup. Saf. Ergo. 2013, 19, 531-541. [CrossRef]

100. Mohamad, D.; Deros, B.M.; Ismail, A.R.; Daruis, D.D.I.; Sukadarin, E.H. RULA analysis of work-related disorder among packaging industry worker using digital human modelong (DHM). In Proceedings of the 2nd International Conference on Ergonomics (ICE 2013), Kuala Lumpur, Malaysia, 2-4 September 2013; Yusuff, R.M., Ahmad, S.A., Daruis, D.D.I., Deros, B.M., Dawal, S.Z.M., Eds.; pp. 9-15.

101. Vignais, N.; Miezal, M.; Bleser, G.; Mura, K.; Gorecky, D.; Marin, F. Innovative system for real-time ergonomic feedback in industrial manufacturing. Appl. Ergon. 2013, 44, 566-574. [CrossRef]

102. Baptista, J.S.; Costa, J.T.; Conceicao, F.; Vaz, M.; Pinto, S.; Guedes, J.; Silva, J.P. Diagnosis of musculoskeletal disorders in manufacturing workers. In Proceedings of the 9th International Symposium on Occupational Safety and Hygiene (SHO), Guimaraes, Portugal, 14-15 February 2013; Arezes, P., Baptista, J.S., Barroso, M.P., Carneiro, P., Costa, N., Melo, R., Miguel, A.S., Perestrelo, G., Cordeiro, P., Eds.; pp. 49-51.

103. Haggag, H.; Hossnv, M.; Nahavandi, S.; Creighton, D. Real time ergonomic assessment for assembly operations using Kinect. In Proceedings of the UKSim-AMSS 15th International Conference on Computer Modelling and Simulation (UKSim), Cambridge, UK, 10-12 April 2013; AlDabass, D., Orsoni, A., Yunus, J., Cant, R., Ibrahim, Z., Eds.; pp. 495-500.

104. Reis, P.F.; Peres, L.S.; Tirloni, A.S.; dos Reis, D.C.; Estrazulas, J.A.; Rossato, M.; Moro, A.R.P. Influence of anthropometry on meat-packing plant workers: An approach to the shoulder joint. Work 2012, 41, 4612-4617. [CrossRef] [PubMed]

105. Chiu, Y.C.; Chen, S.; Wu, G.J.; Lin, Y.H. Three-dimensional computer-aided human factors engineering analysis of a grafting robot. J. Agric. Saf. Health 2012, 18, 181-194. [CrossRef] [PubMed]

106. Miguez, S.A.; Halbeck, M.S.; Vink, P. Participatory ergonomics and new work: Reducing neck complaints in assembling. Work 2012, 41, 5108-5113. [CrossRef] [PubMed]

107. Miguez, S.A.; Pires, C.R.; Domingues, J.L.R. New ways of working in a notebook manufacturing. In Advances in Social and Organizational Factors; Vink, P., Ed.; 2012; pp. 692-700.

108. Naiarkola, S.A.M.; Mirzaei, R. Evaluation of upper limb musculoskeletal loads due to posture, repetition, and force by Rapid Upper Limb Assessment in a textile factory. Health Scope 2012, 1, 18-24. [CrossRef]

109. Wintachai, P.; Charoenchai, N. The comparison of ergonomics postures assessment methods in rubber sheet production. In Proceedings of the IEEE International Conference on Industrial Engineering and Engineering Management (IEEM), Hong Kong, China, 10-13 December 2012; pp. 1257-1261.

110. Gan, Y.H.; Dai, X.Z. Human-like manipulation planning for articulated manipulator. J. Bionic. Eng. 2012, 9, 434-445. [CrossRef]

111. Chiasson, M.E.; Imbeau, D.; Aubry, K.; Delisle, A. Comparing the results of eight methods used to evaluate risk factors associated with musculoskeletal disorders. Int. J. Ind. Ergonom. 2012, 42, 478-488. [CrossRef]

112. Zacharias, F. Knowledge representations for planning manipulation tasks. In Knowledge Representations for Planning Manipulation Tasks; 2012; Volume 16, pp. 1-143.

113. Ozturk, N.; Esin, M.N. Investigation of musculoskeletal symptoms and ergonomic risk factors among female sewing machine operators in Turkey. Int. J. Ind. Ergonom. 2011, 41, 585-591. [CrossRef]

114. Muslim, E.; Nurtjahyo, B.; Ardi, R. Ergonomic analysis of garment industry using Posture Evaluation Index (PEI) in virtual environment. Makara J. Technol. 2011, 15, 75-81.

115. Monteil, N.R.; Vilas, D.D.; Pereira, D.C.; Prado, R.R. A simulation-based ergonomic evaluation for the operational improvement of the slate splitters work. In Proceedings of the 22nd European Modeling and Simulation Symposium (EMSS), Fes, Morocco, 13-15 October 2010; Bruzzone, A., Frydman, C., Longo, F., Mekouar, K., Piera, M.A., Eds.; pp. 191-200.

116. Lopes, O.; Rosario, R. Ergonomic study of a workplace. In Proceedings of the 6th International Symposium on Occupational Safety and Hygiene (SHO 2010), Guimaraes, Portugal, 11-12 February 2010; Arezes, P., Baptista, J.S., Barroso, M.P., Carneiro, P., Cordeiro, P., Costa, N., Melo, R., Miguel, A.S., Perestrelo, G.P., Eds.; pp. 397-400. 
117. Miguez, S.A.; Vink, P.; Hallbeck, M.S. Participatory ergonomics in a mobile factory: Ergonomic device to decrease neck pain. In Advanced in Occupational, Social, and Organizational Ergonomics; Vink, P., Kantola, J., Eds.; 2010; pp. 1-9.

118. Jones, T.; Kumar, S. Comparison of ergonomic risk assessment output in four sawmill jobs. Int. J. Occup. Saf. Ergo. 2010, 16, 105-111. [CrossRef]

119. Eswaramoorthi, M.; John, M.; Rajagopal, C.A.; Prasad, P.S.S.; Mohanram, P.V. Redesigning assembly stations using ergonomic methods as a lean tool. Work 2010, 35, 231-240. [CrossRef]

120. Jones, T.; Kumar, S. Comparison of ergonomic risk assessment output in a repetitive sawmill occupation: Trim-saw operator. Work 2008, 31, 367-376. [PubMed]

121. Jones, T.; Kumar, S. Comparison of ergonomic risk assessments in a repetitive high-risk sawmill occupation: Saw-filer. Int. J. Ind. Ergonom. 2007, 37, 744-753. [CrossRef]

122. Kee, D.; Karwowski, W. A comparison of three observational techniques for assessing postural loads in industry. Int. J. Occup. Saf. Ergo. 2007, 13. [CrossRef] [PubMed]

123. Carnide, F.; Veloso, A.; Gamboa, H.; Caldeira, S.; Fragoso, I. Interaction of biomechanical and morphological factors on shoulder workload in industrial paint work. Clin. Biomech. 2006, 21, S33-S38. [CrossRef] [PubMed]

124. Berger, U.; Lepratti, R.; Otte, H. Application of digital human modelling concepts for automotive production. In Proceedings of the 5th International Symposium on Tools and Methods of Competitive Engineering, Lausanne, Switzerland, 13-17 April 2004; Horyath, I., Xirouchakis, P., Eds.; pp. 365-373.

125. Choobineh, A.; Tosian, R.; Alhamdi, Z.; Davarzanie, M. Ergonomic intervention in carpet mending operation. Appl. Ergon. 2004, 35, 493-496. [CrossRef] [PubMed]

126. Gonzalez, B.A.; Adenso-Diaz, B.; Torre, P.G. Ergonomic performance and quality relationship: An empirical evidence case. Int. J. Ind. Ergonom. 2003, 31, 33-40. [CrossRef]

127. Brown, R.; Li, G.Y. The development of action levels for the 'quick exposure check' (QEC) system. Contemp. Ergon. 2003, 1, 41-46.

128. Cakit, E. Assessment of the physical demands of waste collection tasks. Glob. Nest J. 2015, 17, 426-438.

129. Li, X.M.; Han, S.; Gul, M.; Al-Hussien, M. Automated post-3D visualization ergonomic analysis system for rapid workplace design in modular construction. Automat. Constr. 2019, 98, 160-174. [CrossRef]

130. Li, X.M.; Han, S.; Gul, M.; Al-Hussein, M.; El- Rich, M. Assessment and Work Modification Framework and its Validation for a Lifting Task. J. Constr. Eng. Manag. 2018, 144. [CrossRef]

131. Golabchi, A.; Han, S.; Fayek, A.R. A fuzzy logic approach to posture-based ergonomic analysis for field observation and assessment of construction manual operations. Can. J. Civil Eng. 2016, 43, $294-303$. [CrossRef]

132. Shanahan, C.J.; Vi, P.; Salas, E.A.; Reider, V.L.; Hochman, L.M.L.; Moore, A.E. A comparison of RULA, REBA and Strain Index to four psychophysical scales in the assessment of non-fixed work. Work 2013, 45, 367-378. [CrossRef] [PubMed]

133. Ahmad Nasaruddin, A.F.; Mohd Tamrin, S.B.; Karuppiah, K. The prevalence of musculoskeletal disorder and the association with risk factors among auto repair mechanics in Klang Valley, Malaysia. Iran. J. Public Health 2014, 43, 34-41.

134. Capodaglio, E.M. Occupational risk and prolonged standing work in apparel sales assistants. Int. J. Ind. Ergonom. 2017, 60, 53-59. [CrossRef]

135. Peppoloni, L.; Filippeschi, A.; Ruffaldi, E.; Avizzano, C.A. (WMSDs issue) A novel wearable system for the online assessment of risk for biomechanical load in repetitive efforts. Int. J. Ind. Ergonom. 2016, 52, 1-11. [CrossRef]

136. Rabello, M.V.T.; Costa, D.M.B.; Morgado, C.V. Work-related musculoskeletal disorders in the transportation of dangerous goods. In Proceedings of the 6th International Symposium on Occupational Safety and Hygiene (SHO), Guimaraes, Portugal, 26-27 March 2018; Arezes, P.M., Baptista, J.S., Barroso, M.P., Carneiro, P., Cordeiro, P., Costa, N., Melo, R.B., Miguel, A.S., Perestrelo, G., Eds.; pp. 331-334.

137. Vignais, N.; Bernard, F.; Touvenot, G.; Sagot, J.C. Physical risk factors identification based on body sensor network combined to videotaping. Appl. Ergon. 2017, 65, 410-417. [CrossRef]

138. Wang, W.; Zhang, W.; Feng, W.J. The astronaut ergonomics assessment methodology in microgravity environment. In Proceedings of the 2nd International Conference on Reliability System Engineering (ICRSE), Beijing, China, 10-12 July 2017. 
139. Sayyahi, Z.; Mirzaei, R.; Mirzaei, R. Improving body posture while fueling with a newly designed pump nozzle. Int. J. Occup. Saf. Ergo. 2016, 22, 327-332. [CrossRef]

140. Balaji, K.K.; Alphin, M.S. Computer-aided human factors analysis of the industrial vehicle driver cabin to improve occupational health. Int. J. Injury. Control Saf. 2016, 23, 240-248. [CrossRef]

141. Blackwell, C.J.; Wasas, J.S.; Flanagan, S.P.; Norman, B.A.; Haight, J.M. Grocery shelf stocking tool: Analysis of productivity and human factors. Int. J. Prod. Perform. Manag. 2016, 65, 554-570. [CrossRef]

142. Basahel, A.M. Investigation of work-related musculoskeletal disorders (MSDs) in warehouse workers in Saudi Arabia. In Proceedings of the 6th International Conference on Applied Human Factors and Ergonomics (AHFE), Las Vegas, NV, USA, 26-30 July 2015; Ahram, T., Karwowski, W., Schmorrow, D., Eds.; pp. 4643-4649.

143. Escalona, E.; Hernandez, M.; Yanes, L.; Yanes, L.; Yanes, L. Ergonomic evaluation in a values transportation company in Venezuela. Work 2012, 41,710-713. [CrossRef]

144. Ahmed, M.; Campbell-Kyureghyan, N.; Frost, K.; Bertocci, G. Ergonomic evaluation of a wheelchair transportation securement system. Work 2012, 41, 4924-4930. [CrossRef]

145. Ravnik, D.; Otahal, S.; Fikfak, M.D. Using different methods to assess the discomfort during car driving. Collegium Antropol. 2008, 32, 267-276.

146. Hoy, J.; Mubarak, N.; Nelson, S.; de Landas, M.S.; Magnusson, M.; Okunribido, O.; Pope, M. Whole body vibration and posture as risk factors for low back pain among forklift truck drivers. J. Sound. Vib. 2005, 284, 933-946. [CrossRef]

147. Massaccesi, M.; Pagnotta, A.; Soccetti, A.; Masali, M.; Masiero, C.; Greco, F. Investigation of work-related disorders in truck drivers using RULA method. Appl. Ergon. 2003, 34, 303-307. [CrossRef]

148. Costa, D.M.B.; Ferreira, R.V.; Galante, E.B.F.; Nobrega, J.S.W.; Alves, L.A.; Morgado, C.V. Comparative assessment of work-related musculoskeletal disorders in an industrial kitchen. In Proceedings of the 6th International Symposium on Occupational Safety and Hygiene (SHAO), Guimaraes, Portugal, 26-17 Mars 2018; Arezes, P.M., Baptista, J.S., Barroso, M.P., Carneiro, P., Cordeiro, P., Costa, N., Melo, R.B., Miguel, A.S., Perestrelo, G., Eds.; pp. 325-329.

149. Xu, Y.W.; Cheng, A.S.K. An onsite ergonomics assessment for risk of work-related musculoskeletal disorders among cooks in a Chinese restaurant. Work 2014, 48, 539-545. [CrossRef] [PubMed]

150. Jones, T.; Strickfaden, M.; Kumar, S. Physical demands analysis of occupational tasks in neighborhood pubs. Appl. Ergon. 2005, 36, 535-545. [CrossRef]

151. Ekinci, Y.; Uysal, S.A.; Kabak, V.Y.; Duger, T. Does ergonomics training have an effect on body posture during computer usage? J. Back Musculoskelet. 2019, 32, 191-195. [CrossRef] [PubMed]

152. Levanon, Y.; Lerman, Y.; Gefen, A.; Ratzon, N.Z. Validity of the modified RULA for computer workers and reliability of one observation compared to six. Ergonomics 2014, 57, 1856-1863. [CrossRef]

153. Rasoulzadeh, Y.; Gholamnia, R. Effectiveness of an ergonomics training program on decreasing work-related musculoskeletal disorders risk among video display terminals users. Health Promot. Persp. 2012, 2, 89-95. [CrossRef]

154. Fabrizio, P. Ergonomic intervention in the treatment of a patient with upper extremity and neck pain. Phys. Ther. 2009, 89, 351-360. [CrossRef]

155. Shuval, K.; Donchin, M. Prevalence of upper extremity musculoskeletal symptoms and ergonomic risk factors at a Hi-Tech company in Israel. Int. J. Ind. Ergonom. 2005, 35, 569-581. [CrossRef]

156. Douglas, G.; Long, R. An observation of adults with visual impairments carrying out copy-typing tasks. Behav. Inform. Technol. 2003, 22, 141-153. [CrossRef]

157. Dalkilinc, M.; Bumin, G.; Kayihan, H. The effects of ergonomic training and preventive physiotherapy in musculo-skeletal pain. Pain Clin. 2002, 14, 75-79. [CrossRef]

158. Mohammed, O.; Shell, R.; Swanson, N. Investigating the postural stress associated with sedentary work. In Proceedings of the XIVth Annual International Occupational Ergonomics and Safety Conference 1999, Orlando, FL, USA, 6-9 June 1999; Lee, G.C.H., Ed.; pp. 401-406.

159. Cook, C.J.; Kothival, K. Influence of mouse position on muscular activity in the neck, shoulder and arm in computer users. Appl. Ergon. 1998, 29, 439-443. [CrossRef]

160. Monteiro, L.F.; Martins, F.A.; Felipe, A.; Mattosinho, C.M.D.; Cavalcanti, S.L.; Santos, M.B.G.; Franca, V.V. Ergonomic problem analysis: Applying the Rapid Upper Limb Assessment method in a hospital of the Paulo Afonso /BA/ Brazil. In Proceedings of the 8th International Symposium on Occupational Safety and Hygiene (SHAO), Guimaraes, Portugal, 9-10 February 2012; Arezes, P., Baptista, J.S., Barroso, M.P., Carneiro, P., Cordeiro, P., Costa, N., Melo, R., Miguel, A.S., Perestrelo, G.P., Eds.; pp. 397-402. 
161. Tapia-Araya, A.E.; Uson-Gargallo, J.; Sanchez-Margallo, J.A.; Perez-Duarte, F.J.; Martin-Portugues, I.D.G.; Sanchez-Margallo, F.M. Muscle activity and hand motion in veterinarians performing laparoscopic training tasks with a box trainer. Am. J. Vet. Res. 2016, 77, 186-193. [CrossRef]

162. Lau, N.; Wong, B. Engineering assessment in biomechanics and ergonomic adoptable for designer at early product design phase. In Proceedings of the 12th World Multi-Conference on Systemics, Cybernetics and Indformatics/14th International Conference on Information Systems Analysis and Synthesis, Orlando, FL, USA, 29 June-2 July 2008; Callaos, N., Lesso, W., Zinn, C.D., Baralt, J., Yoshida, E., Eds.; pp. 124-129.

163. Bazazan, A.; Dianat, I.; Feizollahi, N.; Mombeini, Z.; Shirazi, A.M.; Castellucci, H.I. Effect of a posture correction based intervention on musculoskeletal symptoms and fatigue among control room operators. Appl. Ergon. 2019, 76, 12-19. [CrossRef] [PubMed]

164. Cavalini, M.A.; Berduszek, R.J.; Van der Sluis, C.K. Construct validity and test-retest reliability of the revised Upper Extremity Work Demands (UEWD-R) Scale. Occup. Environ. Med. 2017, 74, 763-768. [CrossRef]

165. Rodrigues, M.S.; Leite, R.D.V.; Lelis, C.M.; Chaves, T.C. Differences in ergonomic and workstation factors between computer office workers with and without reported musculoskeletal pain. Work 2017, 57, 563-572. [CrossRef]

166. Tantuco, J.T.; Mirasol, I.V.O.; Oleta, T.A.C.; Custodio, B.P. Postural analysis and assessment of perceived musculoskeletal pain of cleaners in Metro Manila, Philippines. In Proceedings of the International Conference on Physical Ergonomics and Human Factors, Orlando, FL, USA, 27-31 July 2016; Goonetilleke, R., Karwowski, W., Eds.; pp. 255-263.

167. Joines, S.; James, T.; Liu, S.W.; Wang, W.J.; Dunn, R.; Cohen, S. Adjustable task lighting: Field study assesses the benefits in an office environment. Work 2015, 51, 471-481. [CrossRef]

168. Dropkin, J.; Kim, H.; Punnet, L.; Wegman, D.H.; Warren, N.; Buchholz, B. Effect of an office ergonomic randomized controlled trial among workers with neck and upper extremity pain. Occup. Environ. Med. 2015, 72, 6-14. [CrossRef]

169. Quemelo, P.R.V.; Gasparato, F.D.; Vieira, E.R. Prevalence, risks and severity of musculoskeletal disorder symptoms among administrative employees of a Brazilian company. Work 2015, 52, 533-540. [CrossRef]

170. Macedo, A.C.; Azhena, C.F.; Brito, A.P. A case study of ergonomics encompassing white-collar workers: Anthropometry, furniture dimensions, working posture and musculoskeletal disorders. Int. J. Work. Condit. 2014, 8, 31-43.

171. Dalkilinc, M.; Kayihan, H. Efficacy of web-based [e-learning] office ergonomics training: A test study. J. Musculoskelet. Pain 2014, 22, 275-285. [CrossRef]

172. Bell, A.F.; Steele, J.R. Risk of musculoskeletal injury among cleaners during vacuuming. Ergonomics 2012, 55, 237-247. [CrossRef] [PubMed]

173. Taieb-Maimon, M.; Cwilek, J.; Shapira, B.; Orenstein, I. The effectiveness of a training method using self-modeling webcam photos for reducing musculoskeletal risk among office workers using computers. Appl. Ergon. 2012, 43, 376-385. [CrossRef] [PubMed]

174. Lima, T.M.; Coelho, D.A. Prevention of musculoskeletal disorders (MSDs) in office work: A case study. Work 2011, 39, 397-408. [CrossRef] [PubMed]

175. Nam, K.H.; Lee, S.; Kyung, G.; An, J.; An, S. Development of ergonomic gun barrel cleaning method: Automation and its advantages. Hum. Factor. Ergon. Man. 2017, 27, 243-248. [CrossRef]

176. Gentzler, M.; Stader, S. Posture stress on firefighters and emergency medical technicians (EMTs) associated with repetitive reaching, bending, lifting, and pulling tasks. Work 2010, 37, 227-239. [CrossRef]

177. Sellschop, I.V.; Myezwa, H.; Mudzi, W.; Musenge, E. Ergonomic behavior of learners in a digitally driven school environment: Modification using an ergonomic intervention programme. S. Afr. J. Physiother. 2018, 74, a348. [CrossRef]

178. Santiago, J.T.S.; Dizon, P.H.P.; Espina, M.A.C.; Tamayao, M.M. An ergonomic design of senior high school science laboratories in the Philippines. In Proceedings of the AHFE International Conference on Ergonomics in Design, Los Angeles, CA, USA, 17-21 July 2017; Rebelo, F., Soares, M., Eds.; pp. 869-881.

179. Sellschop, I.; Myezwa, H.; Mudzi, W.; Mbambo-Kekana, N. The effect of a computer-related ergonomic intervention program on leaners in a school environment. Work 2015, 51, 869-877. [CrossRef]

180. Chen, J.D.; Falkmer, T.; Parsons, R.; Buzzard, J.; Ciccarelli, M. Impact of experience when using the Rapid Upper Limb Assessment to assess postural risk in children using information and communication technologies. Appl. Ergon. 2014, 45, 398-405. [CrossRef] 
181. Mirzaei, R.; Naiarkola, S.A.M.; Khanoki, B.A.; Ansari, H. Comparative assessment of upper limbs musculoskeletal disorders by Rapid Upper Limb Assessment among computer users of Zahedan universities. Health Scope 2014, 3. [CrossRef]

182. Yahya, M.S.; Palaniandy, T.; Zainun, N.Y.; Mohammad, M. Development of Malaysian primary school children anthropometrics data for designing school furniture parameters. In Proceedings of the 4th International Conference on Mechanical and Manufacturing Engineering (ICME 2013), Bangi Putrajaya, Malaysia, 17-18 December 2013; Ismail, A.E., Nor, N.H.M., Ali, M.F.M., Ahmad, R., Masood, I., Tobi, A.L.M., Ghafir, M.F.A., Muhammad, M., Wahab, M.S., Zain, B.A.M., Eds.; p. 1191.

183. Tavafian, S.S.; Zeidi, I.I.M.; Heidarnia, A.R. Theory-based education and postural ergonomic behaviours of computer operators: A randomized controlled trial from Iran. Turk. Fiz. Tip. Rehab. Dergisi 2012, 58, 312. [CrossRef]

184. Hashim, A.M.; Dawal, S.Z.M.; Yusogg, N. Ergonomic evaluation of postural stress in school workshop. Work 2012, 41, 827-831. [CrossRef] [PubMed]

185. Muslim, E.; Nurtjahyo, B.; Ardi, R. Ergonomic evaluation of a folding bike design using virtual environment modelling. Int. J. Technol. 2011, 2, 122-129.

186. Menendez, C.C.; Amick, B.C.; Chang, C.H.; Harrist, R.B.; Jenkins, M.; Robertson, M.; Janowitz, I.; Rempel, D.M.; Katzh, J.N.; Dennerlein, J.T. Evaluation of two posture survey instruments for assessing computing postures among college students. Work 2009, 34, 421-430. [CrossRef] [PubMed]

187. Kelly, G.; Dockrell, S.; Galvin, R. Computer use in school: Its effect on posture and discomfort in schoolchildren. Work 2009, 32, 321-328. [CrossRef] [PubMed]

188. Breen, R.; Pyper, S.; Rusk, Y.; Dockrell, S. An investigation of children's posture and discomfort during computer use. Ergonomics 2007, 50, 1582-1592. [CrossRef]

189. Ratzlaff, T.D.; Diesbourg, T.L.; McAllister, M.J.; von Hacht, M.; Brissette, A.R.; Bona, M.D. Evaluating the efficacy of an educational ergonomics module for improving slit lamp positioning in ophthalmology residents. Can. J. Ophthalmol. 2019, 54, 159-163. [CrossRef]

190. Van't Hullenaar, C.D.P.; Bos, P.; Broeders, I.A.M.J. Ergonomic assessment of the first assistant during robot-assisted surgery. J. Robot. Surg. 2019, 13, 283-288. [CrossRef]

191. Garosi, E.; Mazloumi, A.; Kalantri, R.; Vahedi, Z.; Shirzhiyan, Z. Design and ergonomic assessment of an infusion set connector tool used in nursing work. Appl. Ergon. 2019, 75, 91-98. [CrossRef]

192. Goyil, N.; DeMayo, W.M.; Hirsch, B.E.; McCall, A.A. Patient positioning during in-office otologic procedures impacts physician ergonomics. Otol. Neurotol. 2018, 39, E883-E888. [CrossRef]

193. Sezgin, D.; Esin, M.N. Effects of a PRECEDE-PROCEED model based ergonomic risk management programme to reduce musculoskeletal symptoms of ICU nurses. Intens. Crit. Care. Nur. 2018, 47, 89-97. [CrossRef] [PubMed]

194. McLaren, W.; Parrott, L. Do dental students have acceptable working posture? Brit. Dent. J. 2018, $225,59-67$. [CrossRef] [PubMed]

195. Van't Hullenaar, C.D.P.; Mertens, A.C.; Ruurda, J.P.; Broeders, I.A.M.J. Validation of ergonomic instructions in robot-assisted surgery simulator training. Surg. Endosc. 2018, 32, 2533-2540. [CrossRef]

196. Li, Z.L.; Baber, C.; Li, F.X.; Macdonald, C.; Godwin, Y. Predicting upper limb discomfort for plastic surgeons wearing loupes based on multi-objective optimization. Cogent Eng. 2017, 4. [CrossRef]

197. Dabholkar, T.Y.; Yardi, S.S.; Oak, S.N.; Ramchandani, S. Objective ergonomic risk assessment of wrist and spine with motion analysis technique during simulated laparoscopic cholecystectomy in experienced and novice surgeons. J. Minim. Access. Surg. 2017, 13, 124-130. [CrossRef]

198. Marcon, M.; Pispero, A.; Pignatelli, N.; Lodi, G.; Tubaro, S. Postural assessment in dentistry based on multiple markers tracking. In Proceedings of the 16th IEEE International Conference on Computer Vision (ICCV), Venice, Italy, 22-29 October 2017; pp. 1408-1415.

199. Govil, N.; DeMayo, W.M.; Hirsch, B.E.; McCall, A.A. Optimizing positioning for in-office otology procedures. Otolaryng. Head Neck 2017, 156, 156-160. [CrossRef]

200. Singh, R.; Carranza, D.; Morrow, M.M.; Vos-draper, T.L.; Mcgree, M.; Weaver, A.; Woolley, S.M.; Hallbeck, S.; Gebhart, J. Effect of different chairs on work-related musculoskeletal discomfort during vaginal surgery. Am. J. Obstet. Gynecol. 2016, 214, S456-S457. [CrossRef]

201. Bensignor, T.; Morel, G.; Reversat, D.; Fuks, D.; Gayet, B. Evaluation of the effect of a laparoscopic robotized needle hoder on ergonomics and skills. Surg. Endosc. 2016, 30, 446-454. [CrossRef] 
202. Shafti, A.; Lazpita, B.U.; Elhage, O.; Wurdemann, H.A.; Althoefer, K. Analysis of comfort and ergonomics for clinical work environments. In Proceedings of the 38th Annual International Conference of the IEEE-Engineering-in-Medicine-and-Biology-Society (EMBC), Orlando, FL, USA, 16-20 August 2016; Patton, J., Barbieri, R., Ji, J., Jabbari, E., Dokos, S., Mukkamala, R., Guiraud, D., Jovanov, E., Dhaher, Y., Panescu, D., et al., Eds.; pp. 1894-1897.

203. Movahhed, T.; Dehghani, M.; Arghami, S.; Arghami, A. Do dental students have a neutral working posture? J. Back Musculoskelet. 2016, 29, 859-864. [CrossRef]

204. Carvalho, F.; Melo, R.B.; Costa, V. Ergonomic work analysis of a pathological anatomy service in a portuguese hospital. In Proceedings of the International Conference on Safety Management and Human Factors, Orlando, FL, USA, 27-31 July 2016; Arezes, P., Ed.; pp. 449-462.

205. Rosso, C.B.; Vieira, L.C.; da Silva, S.L.C.; Amaral, F.G. Work analysis of drug-dispensing process in a hospital emergency pharmacy. Independ. J. Manag. Prod. 2016, 7, 134-150. [CrossRef]

206. Park, H.S.; Kim, J.; Roh, H.L.; Namkoong, S. Analysis of the risk factors of musculoskeletal disease among dentists induced by work posture. J. Phys. Ther. Sci. 2015, 27, 3651-3654. [CrossRef] [PubMed]

207. Sezgin, D.; Esin, M.N. Predisposing factors for musculoskeletal symptoms in intensive care unit nurses. Int. Nurs. Rev. 2015, 62, 92-101. [CrossRef] [PubMed]

208. Tirgar, A.; Javanshir, K.; Talebian, A.; Amini, F.; Parhiz, A. Musculoskeletal disorders among a group of Iranian general dental practitioners. J. Back Musculoskelet. 2015, 28, 755-759. [CrossRef]

209. Bartnicka, J. Knowledge-based ergonomic assessment of working conditions in surgical ward-A case study. Saf. Sci. 2015, 71, 178-188. [CrossRef]

210. Rafie, F.; Jam, A.Z.; Shahravan, A.; Raoof, M.; Eskandarizadeh, A. Prevalence of upper extremity musculoskeletal disorders in dentists: Symptoms and risk factors. J. Environ. Public Health 2015. [CrossRef]

211. Corrocher, P.A.; Presoto, C.D.; Campos, J.A.D.B.; Garcia, P.P.N.S. The association between restorative pre-clinical activities and musculoskeletal disorders. Eur. J. Dent. Educ. 2014, 18, 142-146. [CrossRef]

212. Maulik, S.; Iqbal, R.; De, A.; Chandra, A.M. Evaluation of the working posture and prevalence of musculoskeletal symptoms among medical laboratory technicians. J. Back Musculoskelet. 2014, 27, 453-461. [CrossRef]

213. Roll, S.C.; Selhorst, L.; Evans, K.D. Contribution of positioning to work-related musculoskeletal discomfort in diagnostic medical sonographers. Work 2014, 47, 253-260. [CrossRef]

214. Garcia, P.P.N.S.; Polli, G.S.; Campos, J.A.D.B. Working postures of dental students: Ergonomic analysis using the Ovako Working Analysis System and Rapid Upper Limb Assessment. Med. Lav. 2013, 104, 440-447.

215. Craven, R.; Franasiak, J.; Mosaly, P.; Gehrig, P.A. Ergonomic deficits in robotic gynecologic oncology surgery: A need for intervention. J. Minim. Invas. Gyn. 2013, 20, 648-655. [CrossRef] [PubMed]

216. Noh, H.; Roh, H. Approach of industrial physical therapy to assessment of the musculoskeletal system and ergonomic risk factors of the dental hygienist. J. Phys. Ther. Sci. 2013, 25, 821-826. [CrossRef] [PubMed]

217. Hermandon, J.E.; Choi, S.D. Study of musculoskeletal risks of the office-based surgeries. Work 2012, 41, 1940-1943. [CrossRef] [PubMed]

218. Youssed, Y.; Lee, G.; Godinez, C.; Sutton, E.; Klein, R.V.; George, I.M.; Seagull, F.J.; Park, A. Laparoscopic cholecystectomy poses physical injury risk to surgeons: Analysis of hand technique and standing position. Surg. Endosc. 2011, 25, 2168-2174. [CrossRef]

219. Sung, P.C.; Lee, H.Y.; Ong, C.C.; Chen, C.Y. An ergonomic intervention of the blood testing task for the prevention of WMSDs. In Proceedings of the 9th Pan-Pacific Conference on Ergonomics (PPCOE, Kaohsiung, Taiwan, 7-10 November 2010; Lin, D.Y.M., Chen, H.C., Eds.; pp. 261-265.

220. Statham, M.M.; Sukits, A.L.; Redfern, M.S.; Smith, L.J.; Sok, J.C.; Rosen, C.A. Ergonomic analysis of microlaryngoscopy. Laryngoscope 2010, 120, 297-305. [CrossRef]

221. Sanchez-Margallo, F.M.; Sanchez-Margallo, J.A.; Pagador, J.B.; Moyano, J.L.; Moreno, J.; Uson, J. Ergonomic assessment of hand movements in laparoscopic surgery using the Cyberglove (R). In Proceedings of the Computational Biomechanics Medicine IV, London, UK, 24 September 2009; Miller, K., Nielsen, P.M.F., Eds.; p. 121.

222. Taylor-Phillips, S.; Wallis, M.G.; Gale, A.G. Mammography workstation design: Effect on mammographer behavior and the risk of musculoskeletal disorders-art. No. 69171G. In Proceedings of the Medical Imaging 2008 Conference, San Diego, CA, USA, 17-19 February 2008; Sahiner, B., Manning, D.J., Eds.; p. 9171. 
223. Gandavadi, A.; Ramsay, J.R.E.; Burke, F.J.T. Assessment of dental student posture in two seating conditions using RULA methodology-a pilot study. Brit. Dent. J. 2007, 203, 601-605. [CrossRef]

224. Lee, E.C.; Rafiq, A.; Merrell, R.; Ackerman, R.; Dennerlein, J.T. Ergonomics and human factors in endoscopic surgery: A comparison of manual vs telerobotic simulation systems. Surg. Endosc. 2005, 19, 1064-1070. [CrossRef]

225. Person, J.G.; Hodgson, A.J.; Nagy, A.G. Automated high-frequency posture sampling for ergonomic assessment of laparoscopic surgery. Surg Endosc-Ultras. 2001, 15, 997-1003. [CrossRef]

226. Kilrov, N.; Dockrell, S. Ergonomic intervention: Its effect on working posture and musculoskeletal symptoms in female biomedical scientists. Brit. J. Biomed. Sci. 2000, 57, 199-206.

227. Sahu, S.; Moitra, S.; Maity, S.; Pandit, A.K.; Roy, B. A comparative ergonomics postural assessment of potters and sculptors in the unorganized sector in West Bengal, India. Int. J. Occup. Saf. Ergo. 2013, 19, 455-462. [CrossRef]

228. Kaufman-Cohen, Y.; Ratzon, N.Z. Correlation between risk factors and musculoskeletal disorders among classical musicians. Occup. Med. 2011, 61, 90-95. [CrossRef] [PubMed]

229. Mukhopadhyay, P.; Sriyastaya, S. Ergonomic design issues in some craft sectors of Jaipur. Des. J. 2010, 13, 99-124. [CrossRef]

230. Keester, D.L.; Sommerich, C.M. Investigation of musculoskeletal discomfort, work postures, and muscle activation among practicing tattoo artist. Appl. Ergon. 2017, 58, 137-143. [CrossRef] [PubMed]

231. Mukhopadhyay, P.; Jhodkar, D.; Kumar, P. Ergonomic risk factors in bicycle repairing units at Jabalpur. Work 2015, 51, 245-254. [CrossRef] [PubMed]

232. Oliveira, A.C.; Silva, R.; Domingues, J.P. Work-related musculoskeletal disorders in balneotherapy practitioners. In Proceedings of the 7th International Symposium on Occupational Safety and Hygiene (SHO), Guimaraes, Portugal, 10-11 February 2011; Arezes, P., Baptista, J.S., Barroso, M.P., Carneiro, P., Cordeiro, P., Costa, N., Melo, R., Miguel, A.S., Perestrelo, G.P., Eds.; pp. 447-451.

233. San Antonio, T.; Urrutia, F.; Larrea, A. Ergonomic analysis for people with physical disbilities when the wheelchair is considered as their workstation. In Proceedings of the IEEE Ecuador Technical Chapters Meeting (ETCM), Guayaquil, Ecuador, 12-14 October 2016.

234. Apostoli, P.; Sala, E.; Curti, S.; Cooke, R.M.T.; Violante, F.S.; Mattioli, S. Loads of housework? Biomechanical assessments of the upper limbs in women performing common household tasks. Int. Arch. Occup. Environ. Health 2012, 85, 421-425. [CrossRef] [PubMed]

235. Marino, C.; Santana, R.; Vargas, J.; Morales, L.; Cisneros, L. Reliability and validity of postural evaluations with Kinect v2 sensor ergonomic evaluation system. In Proceedings of the 6th Conference on Information and Communication Technologies of Ecuador (TIC-EC), Riobamba, Ecuador, 21-23 November 2018; BottoTobar, M., BarbaMaggi, L., GonzalezHuerta, J., VillacresCevallos, P., Gomez, O.S., UyidiaFassler, M.I., Eds.; pp. 86-99.

236. Valentim, D.P.; Sato, T.D.; Comper, M.L.C.; da Silva, A.M.; Boas, C.V.; Padula, R.S. Reliability, construct validity and interpretability of the Brazilian version of the Rapid Upper Limb Assessment (RULA) and Strain Index (SI). Braz. J. Phys. Ther. 2018, 22, 198-204. [CrossRef] [PubMed]

237. Halim, I.; Umar, R.Z.R.; Ahmad, N.; Jamli, M.R.; Mohamed, M.S.S.; Albawab, T.M.M.; Abdullah, M.H.L.; Padmanathan, V. Usability study of integrated RULA.-Kinect (TM) system for work posture assessment. Int. J. Integr. Eng. 2018, 10, 175-184. [CrossRef]

238. Umar, R.Z.R.; Ling, C.F.; Ahmad, N.; Halim, I.; Lee, F.A.M.A.; Abdullasim, N. Initial validation of RULA-Kinect system-comparing assessment results between system and human assessors. In Proceedings of the 5th Mechanical Engineering Research Day (MERD), Melaka, Malaysia, 3 May 2018; BinAbdollah, M.F., Ed.; pp. 67-68.

239. Namwongsa, S.; Puntumetakul, R.; Neubert, M.S.; Chaiklieng, S.; Boucaut, R. Ergonomic risk aassessment of smartphone users using the Rapid Upper Limb Assessment (RULA) tool. PLoS ONE 2018, 13, e0203394. [CrossRef]

240. Plantard, P.; Shum, H.P.H.; Le Pierres, A.S.; Multon, F. Validation of an ergonomic assessment method using Kinect data in real workplace conditions. Appl. Ergon. 2017, 65, 562-569. [CrossRef]

241. Can, G.F.; Figlali, N. Image processing based rapid upper limb assessment method. J. Fac. Eng. Archit. Gazi Univ. 2017, 32, 719-731. [CrossRef] 
242. Manghisi, V.M.; Uva, A.E.; Fiorentino, M.; Bevilacqua, V.; Trotta, G.F.; Monno, G. Real time RULA assessment using Kinect v2 sensor. Appl. Ergon. 2017, 65, 481-491. [CrossRef] [PubMed]

243. Son, M.; Jung, J.; Park, W. Evaluating the utility of two gestural discomfort evaluation methods. PLoS ONE 2017, 12. [CrossRef] [PubMed]

244. Nahavandi, D.; Hossny, M. Skeleton-free task-specific Rapid Upper Limb ergonomic assessment using depth imaging sensors. In Proceedings of the 15th IEEE Sensors Conference, Orlando, FL, USA, 30 October-3 November 2016.

245. Ciccarelli, M.; Chen, J.D.; Vaz, S.; Cordier, R.; Falkmer, T. Managing children's postural risk when using mobile technology at home: Challenges and strategies. Appl. Ergon. 2015, 51, 189-198. [CrossRef] [PubMed]

246. Plantard, P.; Auvinet, E.; Le Pierres, A.S.; Multon, F. Pose estimation with a Kinect for ergonomic studies: Evaluation of the accuracy using a virtual mannequin. Sensors 2015, 15, 1785-1803. [CrossRef] [PubMed]

247. Razavi, H.; Behbudi, A. Ergonomic assessment and design of electronic ticket booths in Mashhad city. J. Health Saf. Work 2015, 5, 5.

248. Chihara, T.; Seo, A.; Izumi, T. Total perceived discomfort function for upper limbs based on joint moment. J. Adv. Simulat. Sci. Eng. 2014, 1, 36-50. [CrossRef]

249. Chen, Y.L.; Chiang, H.T. Atilt rolling movement of a gas cylinder: A case study. Work 2014, 49, 473-481. [CrossRef]

250. Son, M.; Park, W.; Jung, J.; Hwang, D.; Park, J. Utilizing sign language gestures for gesture-based interaction: A usability evaluation study. Int. J. Ind. Eng. Theory 2013, 20, 548-561.

251. Dockrell, S.; O'Grady, E.; Bennett, K.; Mullarkey, C.; McConnell, R.; Ruddy, R.; Twomey, S.; Flannery, C. An investigation of the reliability of Rapid Upper Limb Assessment (RULA) as a method of assessment of children's computing posture. Appl. Ergon. 2012, 43, 632-636. [CrossRef]

252. Schlette, C.; Rossmann, J. Motion control strategies for humanoids based on ergonomics. In Proceedings of the 4th International Conference on Intelligent Robotics and Applications (ICIRA 2011), Aachen, Germany, 6-8 December 2011; Jeschke, S., Liu, H.H., Schilberg, D., Eds.; pp. 229-240.

253. Goncalves, P.J.S.; Fernandes, N.O.G. A semi-automatic system for posture risk assessment. In Proceedings of the 16th Annual Scientific Conference on Web Technology, New Media Communications and Telematic Theory Methods, Tools and Applications, London, UK, 18-20 April 2011; AlSaedy, H., Ed.; pp. 64-69.

254. Pires, C.; Lima, F. The contribution of ergonomics in the safety of machinery and equipment. In Proceedings of the 7th International Symposium on Occupational Safety and Hygiene (SHO), Guimaraes, Portugal, 10-11 February 2011; Arezes, P., Baptista, J.S., Barroso, M.P., Carneiro, P., Cordeiro, P., Costa, N., Melo, R., Miguel, A.S., Perestrelo, G.P., Eds.; pp. 527-531.

255. Goncalves, P.J.S.; Fernandes, N.O. RULAmatic-A semi-automatic posture recognition system for RULA risk evaluation method. In Proceedings of the 2nd International Conference on Innovations, Recent Trends and Challenges in Mechatronics, Mechanical Engineering and New High-Tech Products Development (MECAHITECH), Bucharest, Romania, 23-24 September 2010; pp. 266-271.

256. Apostoli, P.; Sala, E. Evidence of work-related musculoskeletal disorders of the upper extremities and current methods of risk assessment: Can Charlie Chaplin give us any suggestions in "Modern Times". La Medicina del lavoro 2009, 100, 384-395.

257. Ward, J.; Riley, C.; Johnson, G. Posture, position \& biometrics: Guidelines for self-service technology. In Proceedings of the Annual Meeting of the Ergonomics-Society, Nottingham, UK; Bust, P.D., Ed.; 2008; pp. 121-126.

258. McGorry, R.W.; Lin, J.H. Power grip strength as a function of tool handle orientation and location. Ergonomics 2007, 50, 1392-1403. [CrossRef] [PubMed]

259. Bao, S.; Howard, N.; Spielholz, P.; Silverstein, B. Two posture analysis approaches and their application in a modified Rapid Upper Limb Assessment evaluation. Ergonomics 2007, 50, 2118-2136. [CrossRef] [PubMed]

260. Lopez-Aragon, L.; Lopez-Liria, R.; Callejon-Ferre, A.J.; Gomez-Galan, M. Applications of the Standardized Nordic Questionnaire: A review. Sustainability 2017, 9, 1514. [CrossRef]

261. Hita-Gutierrez, M.; Gomez-Galan, M.; Diaz-Perez, M.; Callejon-Ferre, A.J. An overview of REBA method applications in the world. Int. J. Environ. Res. Public Health 2020, 17, 2635. [CrossRef]

262. Zink, K.J. Designing sustainable work systems: The need for a systems approach. Appl. Ergon. 2014, 45, 126-132. [CrossRef] 
263. Haslam, R.; Waterson, P. Ergonomics and Sustainability. Ergonomics 2013, 56, 343-347. [CrossRef]

264. Gomez-Galan, M.; Callejon-Ferre, A.J.; Perez-Alonso, J.; Diaz-Perez, M.; Golasi, I. Repetitive movements in melon cultivation workers under greenhouses. Agriculture 2019, 9, 236. [CrossRef]

(C) 2020 by the authors. Licensee MDPI, Basel, Switzerland. This article is an open access article distributed under the terms and conditions of the Creative Commons Attribution (CC BY) license (http://creativecommons.org/licenses/by/4.0/). 